\title{
Time and space model of urban pollution migration: Economy-energy-environment nexus network
}

\author{
Gengyuan Liu ${ }^{\mathrm{a}, \mathrm{b}, *}$, Zhifeng Yang ${ }^{\mathrm{a}, \mathrm{b}}$, Brian D. Fath ${ }^{\mathrm{c}, \mathrm{d}}$, Lei Shi ${ }^{\mathrm{e}}$, Sergio Ulgiati ${ }^{\mathrm{a}, \mathrm{b}, \mathrm{f}}$ \\ ${ }^{a}$ State Key Joint Laboratory of Environment Simulation and Pollution Control, School of Environment, Beijing Normal University, Beijing 100875, China \\ ${ }^{\mathrm{b}}$ Beijing Engineering Research Center for Watershed Environmental Restoration E Integrated Ecological Regulation, Beijing 100875, China \\ ' Biology Department, Towson University, Towson, MD, USA \\ ${ }^{\mathrm{d}}$ Dynamic Systems, IIASA, Laxenburg, Austria \\ e State Environmental Protection Key Laboratory of Eco-industry, School of Environment, Tsinghua University, Beijing 100084, China \\ ${ }^{\mathrm{f}}$ Department of Sciences and Technologies, Parthenope University of Naples, Centro Direzionale-Isola C4, 80143 Naples, Italy
}

\section{H I G H L I G H T S}

- 3E Networks are constructed to untangling the causal web linking urbanization and human health. - Appearance of a cancer village is result of spatial-temporal distribution of human-land interaction.

- Incidences are not just because of surrounding cities also due to far-away city through network.

- Mitigation of the adverse effects of urbanization need to meet the people's health care demands.

\section{A R T I C L E I N F O}

\section{Article history:}

Received 7 December 2015

Received in revised form 28 May 2016

Accepted 29 June 2016

Available online $\mathrm{xxxx}$

\section{Keywords:}

Cancer villages

City

Huaihe river basin

Gravity model

Utility analysis

Ecological network analysis

\begin{abstract}
A B S T R A C T
In recent years, news of "cancer villages" in the Huaihe River Basin filled front and back pages of newspapers and generated elevated concern among readers. This study aims to understand the relationship between the "cancer villages" and the "large cities" around them. A gravity model is constructed to analyze the correlation between "big cities" and "cancer villages" in terms of indices involving economic connections and pollution frequency. Direct and indirect environmental relationships between large cities and "cancer villages" are analyzed using ecological network analysis, in particular the utility analysis method. Results of the pollution-utility analysis showed that cities distant from "cancer villages" can also affect the county through indirect connections. Based on the pollution utility relationship, we found that "cancer villages" both affect and are affected by cities through indirect feedback relationships. It can be inferred that "cancer villages" have a high incidence of malignant disease not only because of the pollution from its surrounding cities but also because of the influence of far-away cities through a network of interactions. In this way, the pollution of "cancer villages" may be heightened with harmful consequences to population health. Considering these indirect connections, not all of the "cancer villages" are able to reduce their pollution by transferring it to another city or county because it can return through indirect pathways. The best approach would be to lower the pollution generation in the first place in order to prevent its impacts, as well as to at least partially mitigate them through more effective medical care.
\end{abstract}

(c) 2016 Elsevier Ltd. All rights reserved.

\section{Introduction}

With reports about "cancer villages" in the Huaihe River Basin by several media outlets since 2004 (Google Map, China's Cancer Villages), the phenomenon has drawn general attention to the fre-

\footnotetext{
* Corresponding author at: State Key Joint Laboratory of Environment Simulation and Pollution Control, School of Environment, Beijing Normal University, Beijing 100875, China.

E-mail address: liugengyuan@bnu.edu.cn (G. Liu).
}

quent occurrences of tumors in the area. In accordance with the tumor death review survey published in the 1970s (Editorial Committee of Tumor Death Maps, 1979), there is a low frequency of tumor mortality upstream of Huaihe River, e.g., gastrointestinal tumors and lung cancer mortality rates are below the national average (the exception is esophageal cancer). However, reported cancer villages now total several dozen along Huaihe River based on media reports since 2004 [1]. Shayinghe River, the largest tributary of Huaihe River, flows through Shenqiu County, where small chemical enterprises and large state-owned chemical enterprises 
working on weaving and painting, leather, and paper production are located upstream [2,3]. The river is also subject to increasing sewage discharge pressure. From Xiangcheng and Shenqiu to Yingshan in Anhui, there have been no less than 10 cancer villages revealed by the media, and many more evidenced by social media such as micro-blogs. ${ }^{1}$ For instance, a volunteer working on longterm environmental protection inspection and publicity discovered more than 20 cancer villages with 100 people suffering from cancer in Shenqiu [4]. Due to the fact that the Huaihe River Basin plays an important role in the economic and social development in China, and to the high incidence of cancer occurrence in this area, research is needed to understand and alleviate this phenomenon.

Published research points out that water pollution is closely related to the high incidence of cancer [5]. The distribution of cancer villages is in close relation to the rivers: nearly $60 \%$ of cancer villages are found within $3 \mathrm{~km}$ of the rivers, and nearly $81 \%$ of cancer villages are located within $5 \mathrm{~km}$ of the rivers [6]. Such finding suggests that the rivers are an important factor affecting cancer distribution. In addition, the "Atlas of water environment and gastrointestinal tumor mortality in the Huaihe River Basin", part of the achievement of the "Correlation assessment study of water pollution and tumor" by the "Eleventh Five-year Plan" National Science and Technology Support Project, was officially published in June, 2013. The atlas, for the first time, confirmed a direct relationship between water pollution and a high incidence of cancer. Regretfully, the existing research lacks an exploration of the relationship of environmental impact between the cities within the river area and adjacent counties, as well as whether cities exert environmental influence on adjacent counties (including on human health). Therefore, this study was conducted for the following purposes: (1) to analyze the influence between cancer villages and the adjacent cities, as well as the strength of influence, (2) to establish a gravity model of the relationship concerning regional characteristic factors (distance, population, economy, and pollution degree) between cancer villages and the adjacent cities; (3) to analyze the relationship between cancer villages and the adjacent rivers and to determine if the high incidence of cancer has a higher correlation with river pollution; (4) to conduct a network analysis of cancer villages in the Huaihe River Basin and large- and mediumsized cities, as well as to determine if there is an indirect link between cancer villages and the adjacent cities; and (5) to provide a reference and policy guidance for research on the formation of cancer villages and cities' pollution impact on cancer villages in the river area.

\section{State of the art}

\subsection{Relationship between urban pollution and the regional environment}

Research on urbanization and urban ecological environments began in China in the 1970s and has continued with a rapid progress [7]. The main focus involves urban environmental effects caused by urbanization, the coordinated urban development of society, economy, and environment, sustainable city development, ecological city, and healthy city development, among others [8].

Water resources and water environmental problems brought about by urbanization include absolute scarcity of water, relative scarcity of water, water pollution, and excess groundwater exploitation. Adopting advanced GIS (Geographic Information System) and RS (Remote Sensing) methods and using numerical simulation, a large number of long-term research projects have been

1 http://s.weibo.com/weibo/\%25E7\%2599\%258C\%25E7\%2597\%2587\%25E6\%259D\% 2591 ? topnav $=1 \&$ wvr $=6 \& b=1$. performed on these topics. For example, Al-Kharabsheh and Ta'any [9] conducted locating and tracking research on urbanization and surface water quality. A bulletin on environmental conditions [10] indicated that surface water pollution is still serious in China due to urban industrial pollution. The water quality of the seven waters (Yangtze River, Yellow River, Zhujiang River, Songhuajiang River, Huaihe River, Haihe River, and Liaohe River) is basically the same as the year of 2007. The overall water quality in the Zhujiang and Yangtze rivers is good, while the Songhuajiang River remains lightly polluted. The Yellow River, Huaihe River, and Liaohe River remain moderately polluted, and the Huaihe River is seriously contaminated. Among the 26 lakes and reservoirs monitored for nutritional status, $46.2 \%$ are eutrophic. DeNooyer et al. [11] focused on the state of Illinois, combined existing digital spatial datasets with engineering basic principles to synthesize a geographic information systems (GIS) model of current and projected water demand for thermoelectric power plants. Nanduri and Saavedra-Antolinez [12] developed a CMDP model for the energ $\mathrm{y}$-water-climate change nexus.

Zhang [13] says that the expansion of cities has provided humans with favorable living and working environments but also caused considerable harm to the urban environment due to pollutant emissions from factories and daily life. Because of rainfall, the pollutants will spread, move, and then be deposited in new locations. Due to the fact that pollutants in the atmosphere are soluble in or carried by water, they can be transferred to the ground, underground, and even to remote areas, affecting the downwind or downstream areas. Industrial sewage also flows through sewers into rivers and lakes, contaminating surface water and even groundwater by means of the soil. Gao et al. [14] states that with the quickening pace of urbanization in China and the rapid development of industrialization, population growth, and gradual improvement of people's living standards, water consumption has dramatically increased, and industrial waste water and urban sewage emissions are rapidly increasing. Thus, the conflict between the shortage of water resources and economic and social development is becoming more intense. Wang et al. [15] showed evidence that the increasing amount of industrial pollution in rural areas directly results in the deterioration of rural water, soil, and air; the livelihood and health of the masses of rural farmers are seriously affected; and the rural areas pay a huge price for the rapid growth of Zhejiang province. Xu [16] indicates in his study of ecosystem health problems in Dianchi Basin that pollution control acts as the key to reach the functional standard of the river basin water environment. Briefly, the environmental carrying capacity of rivers has two connotations: quantity and space. Thus, aside from the control of emissions, the layout of the pollutant source is of great importance to successfully reach water environment quality standards.

Several scholars have conducted research into the relationship between urban pollution migration and regional ecological impact. Regarding the issue of the relocation of pollution-causing enterprises, a geographical analysis method is usually adopted, including the urban land use model by Burgess [17], the backwash effects and spread effects by Myrdal [18], and the polarization effects by Hirschman [19]. These traditional methods still play an important role in today's resource management and allocation. For example, Ahlfeldt [20] found the mono-centric model useful in certain conditions, and Arauzo-Carod et al. [21] concludes that the relationship between econometric methods and related location theories is relatively weak concerning the relocation of pollution-causing enterprises. In their estimation, an increasing number of scholars will study the relocation of pollution-causing enterprises after the appearance of a new data collection strategy and solution to the problem of data sources. Liu et al. [22] used an extended STIRPAT model to investigate the effects of human 
activity on energy consumption and three types of industrial pollutant emissions (exhaust gases, waste water and solid waste) at the national and regional levels and tested the environmental Kuznets curve (EKC) hypothesis based on a balanced provincial panel dataset in China over the period 1990-2012. The results show that because of the regional disparities in anthropogenic impact on the environment, formulating specific region-oriented energy saving and emission reduction strategies may provide a more practical and effective approach to achieving sustainable development in China. Xing et al. [23] determined the influence of backwash effects and spread effects in Changsha, Zhujiang River, and Xiangtan in China, while Forrer et al. [24] found that the key cities of China have exerted a backwash effect on the nearby rural counties and villages and a spread effect on other cities. Unfortunately, these geographical methods have not been widely applied to the study of sustainable development.

\subsection{Spatial distribution of affected areas}

Studies demonstrate that the distribution of cancer villages is not arbitrary in space $[6,25]$. It is, instead, closely correlated with geographical factors, such as distance from and direction to cities, with economy size, population, and environment pollution. Moreover, one characteristic of the high incidence of cancer near the Huaihe River is that gastrointestinal tumors are especially prevalent, not on both sides of the river but near first and second category tributaries, even smaller tributaries, and villages within $2.5 \mathrm{~km}$ of polluted tributaries.

Scientific studies about cancer villages, at present, mainly focus on two aspects: (1) the cause and (2) their temporal (The Third Death Review Survey Report, 2008; Report of Cancer Death in China, 2010; [26-28] and spatial distribution [29-31]. For instance, Wang et al. [26] researches cancer villages in Shaanxi Province and a geochemical element analysis of seven samples (water, flour, beans, potatoes, tomatoes, soil, and rocks) from the cancer village in Huaxian County, as well as trace element analysis of samples of hair. The preliminary conclusion of this work is that arsenic, lead, and cadmium pollution is the major cause of cancer in this village. Lin [27] points out that total coliform group and total bacteria in the groundwater of this village exceed standards by up to $100 \%$ and $41.2 \%$, respectively; the nitrate nitrogen concentration also averages $15.2 \mathrm{mg} / \mathrm{L}$. The conclusion is that drinking water contaminated with polluted groundwater is related to the high incidence of cancer in that area. In addition, Yu and Zhang [32] collect reports of cancer villages from academic papers and online media, summarize the present state of cancer villages in China, and analyze the relationship between the occurrence and development of cancer villages and pollution (especially water pollution) and macro-social and economic environments. The authors conclude that cancer villages, as a typical environmental health problem, are closely related to environmental pollution, especially water pollution.

To date, very little research has been performed on the temporal and spatial distribution of cancer villages. Gong and Zhang [6] reached the following conclusions: (1) Between 2000 and 2009 were "times of high occurrence of cancer villages" in China because $53 \%$ of new cancer villages appeared in that decade, and this may be related to the number of badly polluted villages caused by the large scale development of township enterprises in the 1980s. (2) The distribution model of cancer villages in China has a typical concentration with a certain regional differences effect following the river flow direction, i.e., there are more cancer villages in east China than in the central China and more in the central China than in west China, generally. Based the latest research of cancer statistics in China [33], the research shows the significant differences in cancer incidence rates for all cancers combined by place of resi- dence (rural vs urban and between regions) in China. Rural residents have higher incidence compared with their urban counterparts, and incidence rates varied substantially across the 7 administrative regions. Besides, there are greater geographic variations in cancer mortality and the survival proxies across China. It is likely that at least part of these geographic disparities could be explained by the more limited medical resources, lower levels of cancer care, and a larger proportion of patients diagnosed with cancer at a late stage in rural and underdeveloped areas in China [34].

In our opinion, the emergence of the cancer villages is the result of the evolution of the relationship between humans and land, while its space-time distribution and its changes are a geography related health problem. However, few studies concentrate on the exploration of the space-time distribution and the relationship with adjacent cities, thus calling for additional research.

\section{Description of the system}

Located in the eastern part of China, the Huaihe River Basin lies between the Yellow River and the Yangtze River $\left(111^{\circ} 55^{\prime} \mathrm{E}\right.$ to $111^{\circ} 45^{\prime} \mathrm{E}, 30^{\circ} 55^{\prime} \mathrm{N}$ to $\left.36^{\circ} 20^{\prime} \mathrm{N}\right)$. The Huaihe River Basin covers five provinces (Hubei, Henan, Anhui, Jiangsu, and Shandong), 35 cities, and 189 counties. The total population is about 165 million, with an average population density of 611 people $/ \mathrm{km}^{2}$, i.e., 4.8 -fold higher than the national average population density, thus ranking first in population density among river basins in China [35]. The total change in elevation along the $1000-\mathrm{km}$-long river course is about $200 \mathrm{~m}$. The upstream and midstream portions of Huaihe River are characterized by numerous inflows, with 16 tributaries that cover $>2000 \mathrm{~km}^{2}$. Near the Huaihe River, the population has been increasing, industrial and agricultural production have experienced rapid development, and township enterprises have maintained an upward trend since the 1990s.

However, along with development of the urban economy, urban pollution is becoming an increasingly serious problem. Waste flows, such as sewage, industrial waste, urban waste, industrial residues, medical waste, pesticides and fertilizers used in farmland mostly flow along with heavy rain into rivers, resulting in severe pollution across the Huaihe River basin. Statistically, the Yinghe River and Shahe River receive waste water from $>30$ cities from Zhengzhou to Xiangcheng, with an average amount of up to 1.662 million tons per day. Five counties (or cities) in Fuyang, Anhui Province, discharge 138,000 tons of sewage daily, severely contaminating the Kuihe River, Xinbianhe River, and Suihe River and aggravating Huaihe River's quality. Indeed, Huaihe River water pollution has become a major societal concern in all walks of life (see Fig. 1).

\subsection{Environmental quality data of surface water in the Huaihe River basin}

The 2004-2006 data used for environmental quality analysis of surface water in the Huaihe River basin were obtained from the series Environmental Quality Reports (EQR) of the People's Republic of China. The annual EQRs were initially published by the State Environmental Protection Administration (SEPA) in 2004-2006. SEPA was replaced by the Ministry of Environmental Protection (MEP), so reference was made to the MEP's reports published in 2009-2010. Specifically, the water quality monitoring data for the nationally controlled sections of the Huaihe River were used for analysis, which included the water quality grades and corresponding monitoring indicators. The Huaihe River basin was divided into different sections to monitor water quality, with the number of sections varying prior to 2003 (please refer to Fig. B1: 


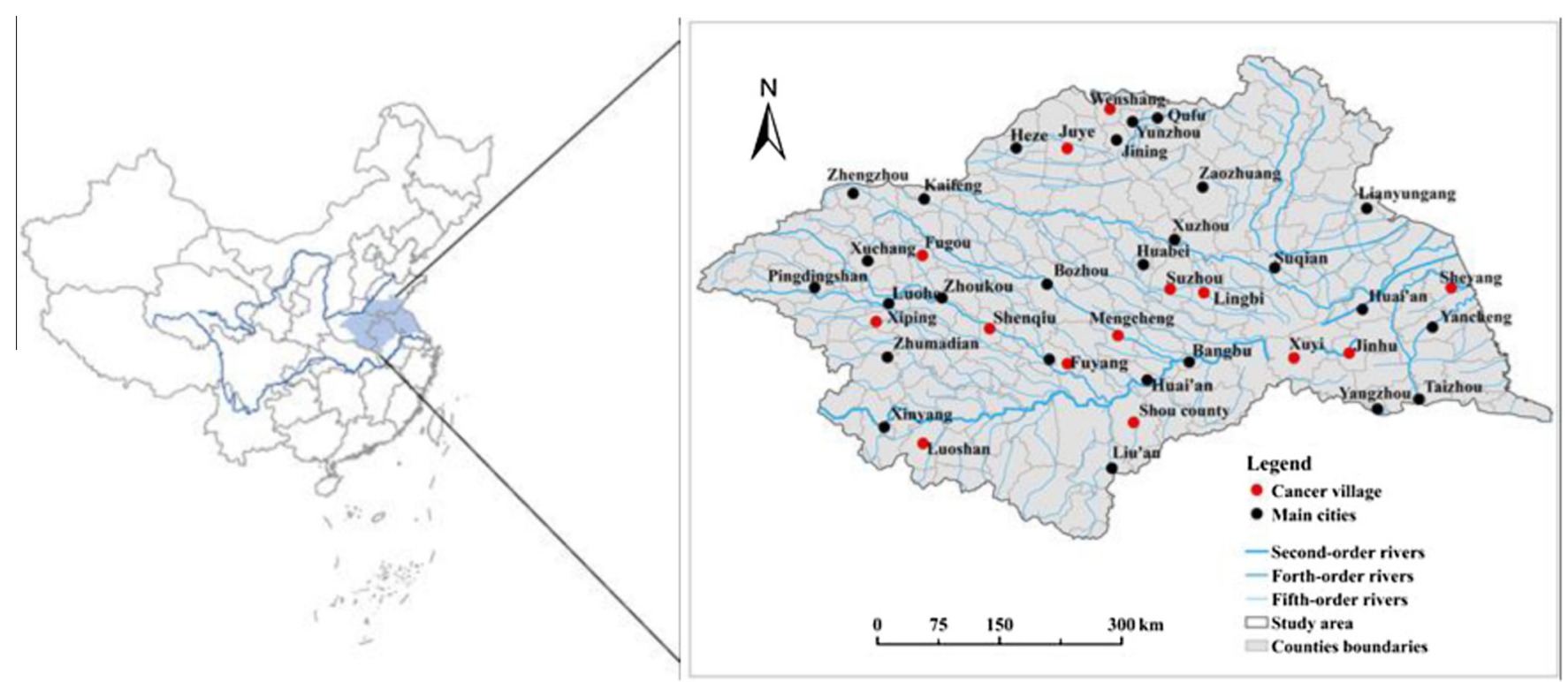

Fig. 1. The "cancer villages" in the Huaihe River Basin and the adjacent urban area (modified from Yang and Zhuang, 2013).

River system of the Huaihe River basin and its water quality monitoring sections in Appendix B). In 2003, the number of nationally controlled sections was fixed at 86 , comprising 14 and 72 sections along the main river and its tributaries, respectively (please refer to the Appendix B, Fig. B1).

For the selected data, although some annual EQRs graded the water quality of the various sections, the concentration levels of the indicators used and corresponding grades were not provided. For some years, the concentration levels of the water quality indicators were directly provided instead. Water quality data that had not been graded in the EQRs were categorized based on the national water quality standards (GB3838-1988 and GB38382002). The main monitoring indicators used for grading water quality included ammonia/un-ionized ammonia, biochemical oxygen demand (BOD), chemical oxygen demand (COD), and volatile phenols. Un-ionized ammonia refers to nitrogen $\left(\mathrm{NH}_{3}\right)$ that exists in water in the form of free ammonia, while ammonia nitrogen is the sum of free ammonia in water and ammonium ion $\left(\mathrm{NH}_{4}^{+}\right)$. BOD is the total amount of oxygen dissolved in water that is used by microorganisms for oxidative decomposition of organic matter. As a result of this biological action, organic matter in the water becomes mineralized or gasified. For COD, a chemical oxidant (such as potassium permanganate) is used for oxidative decomposition of oxidizable substances in the water (including organic matter, nitrites, ferrous salt, and sulfides), followed by the calculation of oxygen consumption based on the amount of residual oxidant. Volatile phenols usually refer to phenols with boiling points $<230^{\circ} \mathrm{C}$. These monohydric phenols are highly toxic substances.

For a particular section where the observational data on water quality were available for a sufficient period of time, its water quality situation would also be reflected by the number of times the Grades V-sub-V group (polluted) appeared as a ratio (frequency) of the total number of observations. That ratio was defined as the frequency of water pollution and calculated as follows:

$F W P=Y_{p} / Y$

where $Y_{p}$ is the number of times that Grades $\mathrm{V}$-sub-V appeared within a specific observational period, and $Y$ represents the total number of observations (which could be on a monthly or annual basis). The water quality Grades $\mathrm{V}$-sub-V referred to in the formula could be the water quality grade obtained after comprehensive evaluation or the concentration grade of a single water quality monitoring indicator. Considering some sections have incomplete data for certain years, Grades V-sub-V water quality for these sections were mainly computed using those years for which monitoring data were available. If the monitoring data for a selected section were missing for a particular year, that year was not included in the computations (see Fig. B2 in Appendix B).

\subsection{Death surveillance data of the population in the Huaihe River basin, 2004-2006}

In 2005, the Chinese Center for Disease Control and Prevention performed studies on malignant tumors and their related risk factors among the population of the Huaihe River basin at three key locations. In 2007, based on this study, the China CDC performed a 3-year retrospective investigation into the causes of death. A total of 14 counties along the main Huaihe River and its main tributaries were selected for the study, generating the data of the population's cause of death during 2004-2006. This investigation was a sub-section of the national survey on causes of death and epidemiology. Using the compiled data, the China CDC established a comprehensive monitoring system for the causes of death, illnesses, births, and birth defects. This system covers a population of 12.64 million, which comprised $8 \%$ of the total regional population of the Huaihe River basin at that time. The 14 counties monitored by the China CDC were distributed among six of the aforementioned zones used for our analysis of water quality, specifically the eastern downstream region, central eastern plains, western hilly and mountainous region, central western plains, southern plains, and drainage basin of Nansi Lake (see Fig. B3 in Appendix B).

The determination of causes of death for residents living in the areas being monitored were as follows: (i) for those who passed away in the hospital, cause of death was stated on the medical certificate of death filled out by the attending physician; or (ii) for those who died at home, reference was made to the hospital's diagnosis. If that hospital ranks lower than a rural hospital or when the tumor diagnosis was made by a hospital that is outranked by a 
county hospital, a trained doctor from the rural hospital used the autopsy inference scale and the residents' medical information before death to fill out the certificate for the inferred cause of death. The local county $C D C$ then submitted the medical certificates of death and certificates for the inferred cause of death to the China CDC through a network platform of the national system for death reporting. The monitoring and analysis report for the causes of death for the population of the Huaihe River basin was completed annually.

\subsection{Changes in gastrointestinal cancer deaths among the population of the Huaihe River basin}

The increase in tumor mortality rates in these areas was related to changes in mortality rates by several major gastrointestinal cancers. This collection described, in detail, changes in the mortality rates of liver, stomach, and esophageal cancers within the Huaihe River basin.

\section{- Hepatic/liver cancer}

In the period of 1973-1975, incidences of liver cancer in the Huaihe River basin were low. The exceptions were the counties of Jinhu, Xuyi, and Sheyang located downstream, for which the population had a higher mortality rate from liver cancer than the national average. The mortality rate for most of the counties (districts) was lower than the national average, including those located along the Level 1 tributaries in the western plains at the mid- and up-stream portions of the Huaihe River: Shenqiu and Yingdong (on the banks of the Shaying River), Fugou and Mengcheng (Wo River), Yongqiao and Lingbi (Kui River), Xiping (Hong River), and Wenshang and Juye (located at the basin of the Yi-Shu-Si Rivers). The rates of these counties were approximately $50 \%$ of national average, with a small number of other counties being consistent with the national average (please refer to the 1973-1975 standardized hepatic cancer mortality rates for males and females, respectively).

However, the mortality rates due to liver cancer for the population of these regions was generally higher than the national average by the period of 2004-2006. This was especially so for the populations in the basins of the Shaying, Kui, and Wo Rivers, where the mortality rates were $1.45-1.86$ times that of the national average. Of greater concern was that over the three decades, the increase in death rates of these populations with originally low incidences doubled that of the national average, with Shenqiu reaching 5.43 times the national average.

\section{- Gastric/stomach cancer}

Incidences of gastric cancer in the Huaihe River basin in 19731975 were also low. The exceptions were the counties of Jinhu, Xuyi, and Sheyang located downstream, for which the population had a higher mortality rate from gastric cancer than the national average. The mortality rates for the other regions was generally $40-80 \%$ of the national average (please refer to the 1973-1975 standardized gastric cancer mortality rates for males and females, respectively).

By 2004-2006, most of the counties (districts) that originally had low incidences of gastric cancer deaths exhibited increasing trends of rates higher than the national average. In particular, the rate for Shenqiu increased by 2.56 times compared to that in 1975. For Jinhu and Sheyang Counties, which originally had high incidences, the rates remained higher than the national average. However, the decline in rate was faster than the national average, leading to a narrower gap between the two rates.

\section{- Esophageal cancer}

In the period of 1973-1975, there were high incidences of esophageal cancer in the mid- and down-stream areas of the Huaihe River and Subei region. Certain areas on the south bank of the Huaihe River, within the river's drainage basin (in Shandong Province), and upstream (in Henan Province) also had high incidences. The low-incidence areas were located in the central eastern plains of the Huaihe River, where the rates were $60-80 \%$ that of the national average. For the populations of most of the regions, the esophageal cancer mortality rate was equivalent to or slightly lower than the national level.

Corresponding to the 14 counties (districts) being monitored, the four counties of Jinhu, Xuyi, Sheyang, and Yingdong had mortality rates higher than the national average. For the remaining cities and counties, the esophageal cancer mortality rates of the population were equivalent to or slightly lower than the national level.

In the period of 2004-2006, the mortality rates of the population in most of the regions in the 14 counties (districts) of the Huaihe River basin being monitored exhibited a downward trend, as was the case with the national level. However, the rate of decline was slower than the national rate, resulting in a higher than national level mortality rate. The mortality rates of areas originally with low or normal incidences, including Shenqiu, Shou County, Yingdong, Lingbi, and Mengcheng at the western plains along the mid- and up-stream of the Huaihe River, as well as Wenshang and Juye of the Yi-Shu-Si Rivers basin, exceeded the national average. This was especially so for Shenqiu and Yongqiao (the former Su County), where the rising rates transformed these areas from normal to high incidences of esophageal cancer. However, there was generally a downward trend in esophageal cancer mortality rates for the population of most of the counties (districts) being monitored.

\section{Methods}

\subsection{Gravity model methods to assess economic and pollution flows} between cancer villages and adjacent cities

Cancer villages are products of a certain historical stage of economic and social development, closely related to regional economic development. In addition, a high incidence of cancer has been confirmed to have a close tie to environmental pollution. Therefore, the flows between cancer villages and adjacent cities that we focused on are mainly economic and pollution relationships.

Economic relations are one of the manifestations of spatial interaction between cities. In theory, the interaction between cities is positively correlated with city scale and negatively correlated with the distance between the cities (gravity model). The gravity model was selected to calculate the economic relationships between 14 cancer areas and their adjacent big cities. The gravity model approach is often used to analyze economic performance among cities. Western regional economists and geologists have long applied Newton's gravity hypothesis in physics to the study of economic space. The law of universal gravitation states that attraction between two objects is in direct proportion to their respective qualities and inversely proportional to the distance between the two. In 1880, the English demographer Ravenstein applied the gravity model to population analysis, starting the use of Newton's gravity model to the research of social science. Reilly (date) put forward the famous Reilly Formula in the 1930s, spreading the gravity model to field of social economy in a real sense. That formula was applied so widely in economy and society that classical textbooks referred it as Reilly's Law of Retail Gravitation [10]. American geographer Tobler [36] developed a gravity model 
Table 1

Main methods and indices of ENA methodology.

\begin{tabular}{|c|c|c|}
\hline Analytic method & Goals and applications & Indices \\
\hline Throughflow analysis & $\begin{array}{l}\text { Calculates the flow parameters of material and energy of each compartment within the } \\
\text { ecosystem }\end{array}$ & TST, APL, FCI, etc. \\
\hline Structural analysis & Represents interconnection patterns between compartments in digraph or adjacency matrix & Pathways numbers, pathway length \\
\hline Storage analysis & Identifies non-dimensional storage intensities along indirect pathways & Storage mass, retention time \\
\hline Utility analysis & $\begin{array}{l}\text { Analyzes the direct and indirect relationships between components and the mutualism they } \\
\text { perform of the concerned ecosystems }\end{array}$ & $\begin{array}{l}\text { Integrated mutualism index, synergism } \\
\text { rate }\end{array}$ \\
\hline Control analysis & Analysis of the control each component exerts in the overall system configuration & Flow dependency, control distribution \\
\hline $\begin{array}{l}\text { Trophic (food web) } \\
\text { analysis }\end{array}$ & Calculates the trophic level of species and identifies the existence of cycles within the ecosystem & Integrated trophic level, trophic chains \\
\hline $\begin{array}{l}\text { Information- } \\
\text { theoretical analysis }\end{array}$ & $\begin{array}{l}\text { Quantifies the performance (like development status, diversity and maturity) of the system as a } \\
\text { whole at processing material and energy }\end{array}$ & $\begin{array}{l}\text { Developmental capacity, ascendancy, } \\
\text { overload, redundancy }\end{array}$ \\
\hline
\end{tabular}

measuring economic relation performance among cities based on Newton's gravity model. According to this model, the interaction between different cities (i.e., the economic relation performance) is proportional to the two cities' social and economic scale and is inversely proportional to the square of the distance between the cities. Since then, a number of scholars have revised each of the parameters in the model on the basis of practical problems, continuously improving and applying this model. Several scholars in China also use the interaction force in this model to perform a large number of empirical analyses, verifying that the economic relation performance between cities is influenced by economic scale and their distance. With the gravity model approach, Gu and Pang [37] conducted a quantitative calculation of space intensity between Chinese cities, describing the space link and nodule area structure of China's urban system. Tang et al. [38] measures the economic relation performance and the strength of economic linkage between different cities in the Huaihai economic zone based on the gravity model and the model of integrated passenger transportation. Additionally, they analyze the urban economic radiation and membership. Using the potential model, Xue (2008) divides the economic impact area of 31 provincial capitals in China, sums their overall distribution characteristics, and studies the composition of different economic impact areas and their distribution across the provinces. The authors comprehensively analyze the provincial capitals' economic impact areas and provincial administrative scope and conclude that there are four types of spatial relationships. Based on the economic potential model, Wu (2010) performed a study on the comprehensive transportation planning of Shanghai and Ningbo, providing a development model and reference for other urban and economic transportation projects.

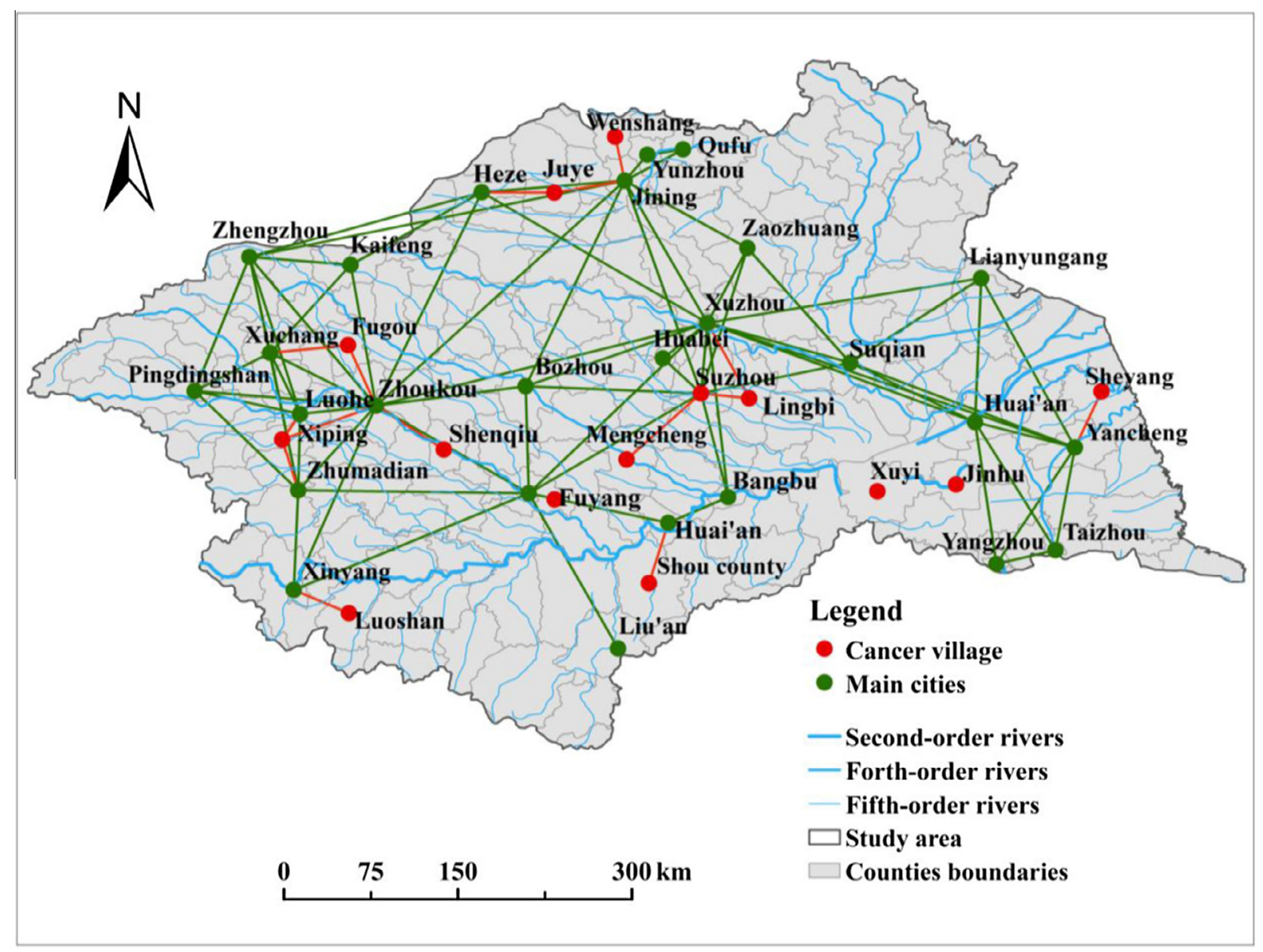

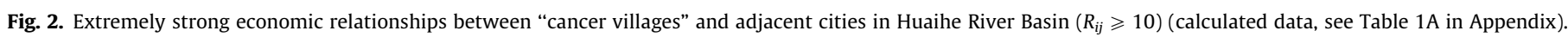




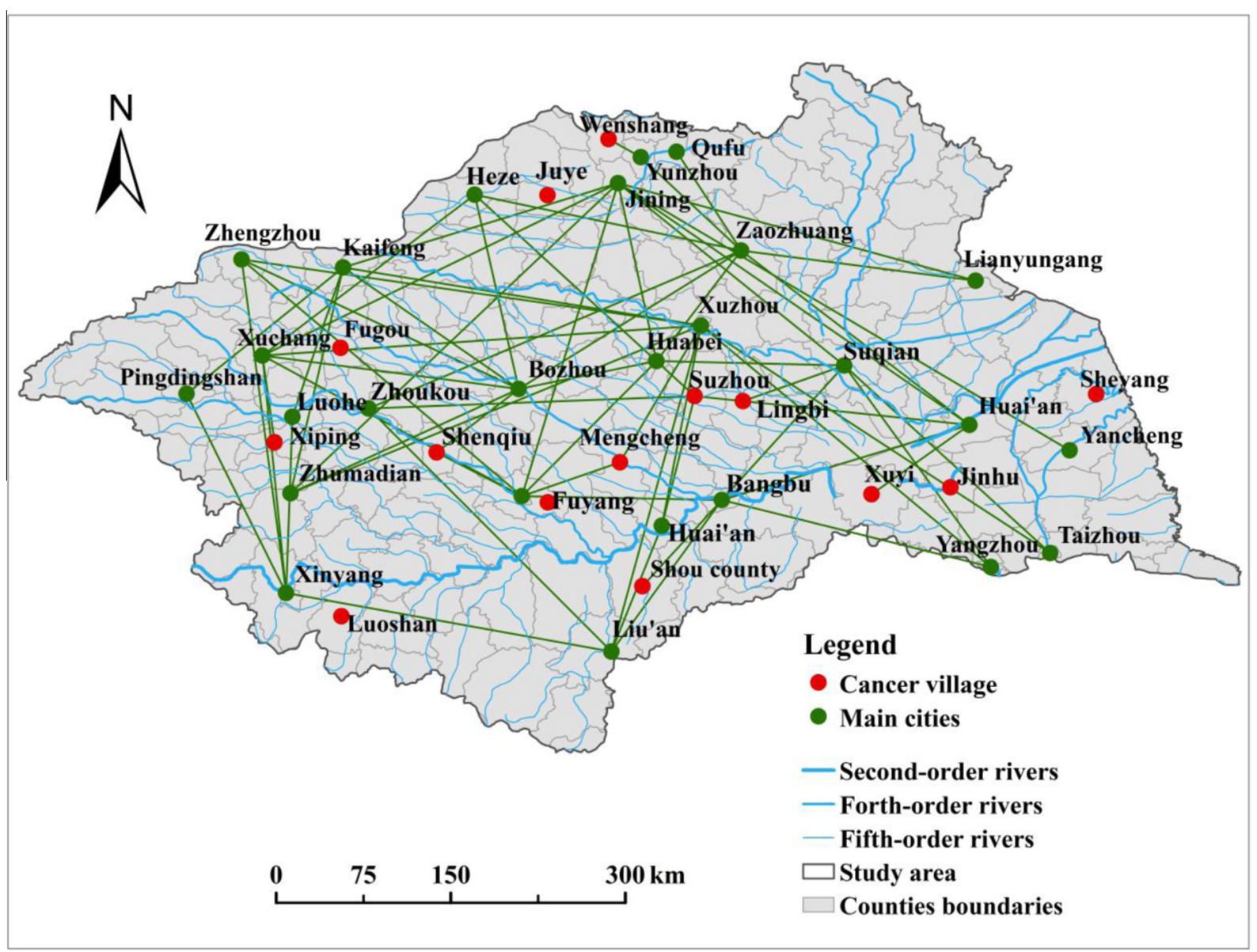

Fig. 3. Weak economic relationships between "cancer villages" and adjacent cities in Huaihe River Basin $\left(0.5 \leqslant R_{i j} \leqslant 5\right)$ (calculated data, see Table $1 \mathrm{~A}$ in Appendix).

In this study, the gravity model is usually expressed as:

$I_{i j}=G P_{i} P_{J} / d_{i j}^{r}$

where $I_{i j}$ refers to the gravity between the two cities (i and j), $P_{i}$ and $P_{j}$ refer to the "city quality", $d_{i j}$ refers to the distance between the two cities, $G$ refers to the gravity coefficient, and $r$ refers to the gravity attenuation coefficient (in most cases $=2$ ) [39].

In practice, the gravity coefficient $G$ has no correlation with urban economic gravity, but the contents of $P$ and $d$ must be redefined, which affects the entire formula. Therefore, the expression is restructured as:

$I_{i j}=P_{i} P_{j} / d_{i j}^{2}$

In this expression, $P_{i}$ and $P_{j}$ can be measured by different methods, and we selected a single index to measure "city quality", such as GDP, $N$ (total population), $V$ (pollution degree). Here, we use $P=\sqrt{G D P \times N}[40]$.

Specifically, the following formula shows the calculation of economic relation and the pollution relation:

$R_{i j}=\left(\sqrt{G D P_{i} N_{i}} \times \sqrt{G D P_{j} N_{j}}\right) / d_{i j}^{2}$

where $i$ refers to one city (No. 1 ), $j$ refers to the other city (No. 2), $R$ represents the economic relationship between the two cities, $N$ refers to the city's population (unit = ten thousand), GDP refers to the annual gross domestic product (unit=one hundred million Yuan), and $d$ refers to the distance between the two cities (unit $=\mathrm{km}$ ).
What an economic relationship means is that when cities No. 1 and No. 2 have some economic linkage, they affect each other's economic conditions, and the economic relationship is used to represent the strength of the ties. Obtaining the specific numerical value of the economic relationships between the 14 monitored counties and the adjacent cities, the data can be used in a matrix of the economic relationship, and GIS technology can be used to generate a distribution diagram for the economic relationships in the targeted research areas.

Similarly, we used the gravity model to determine the pollution relationship between cancer villages and their adjacent cities. We input the interpreted data of urban pollution, population data, and the distance from cancer villages to their adjacent cities into the gravity model to measure this relationship using the formula:

$S_{i j}=\left(\sqrt{V_{i} N_{i}} \times \sqrt{V_{j} N_{j}}\right) / d_{i j}^{2}$

where $i$ refers to one city (No. 1), $j$ refers to the other city (No. 2), $S$ refers to the pollution relationship, $N$ refers to the city's population (unit = ten thousand), $V$ refers to the pollution degree, and $d$ refers to the distance between the two cities ( $\mathrm{unit}=\mathrm{km}$ ).

\subsection{Methodology for assessment of cancer villages based on Ecological Network Analysis (ENA)}

Since Hannon, Patten, and Finn first published their papers on the analysis of flows in ecological networks (Hannon 1973; Finn, 1976; [41], there have been multiple studies of methods for and applications of ecological network analysis. Among them, Ulanowicz [42], Ulanowicz [43] emphasized a combination of transactive 


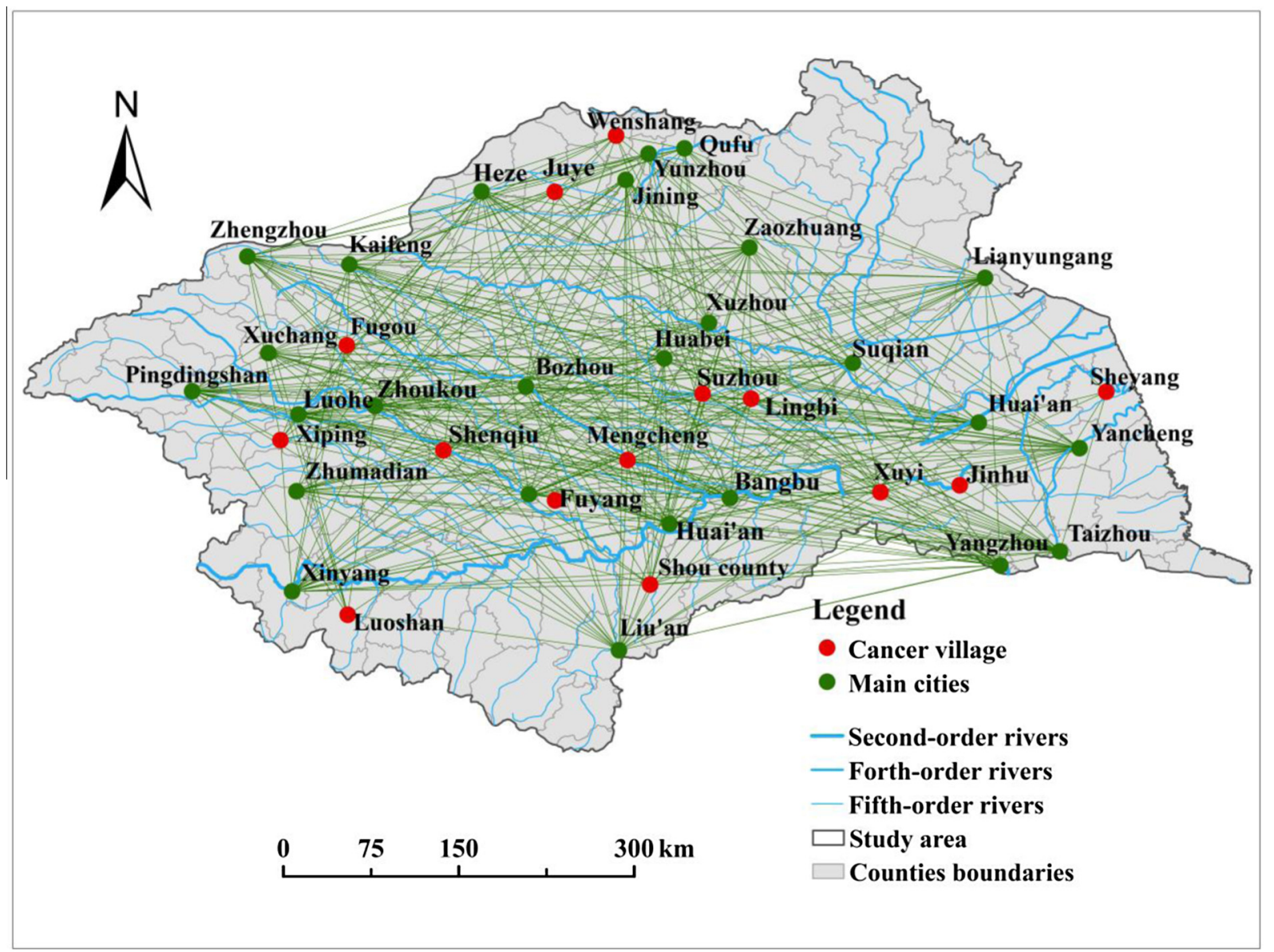

Fig. 4. Negligible economic relationships between "cancer villages" and adjacent cities in Huaihe River Basin $\left(R_{i j}<0.5\right)$ (calculated data, see Table $1 \mathrm{~A}$ in Appendix).

Table 2

Extremely strong economic scores between "cancer villages" and adjacent cities in Huaihe River Basin.

\begin{tabular}{|c|c|c|c|c|c|c|c|c|c|c|c|}
\hline & Wenshang & Juye & Fugou & Xiping & Shenqiu & Luo & Mengcheng & Lingbi & Shou & Xuyi & Sheyang \\
\hline Jining & 50.21 & 32.39 & 0.80 & 0.67 & 1.20 & - & 1.47 & 1.49 & 0.76 & 0.66 & - \\
\hline Qufu & 2.66 & 0.85 & - & - & - & - & - & - & - & - & - \\
\hline Yanzhou & 6.30 & 1.61 & - & - & - & - & - & - & - & - & - \\
\hline Heze & 3.55 & 11.45 & 1.14 & 0.72 & 1.18 & - & 0.88 & 0.65 & - & - & - \\
\hline Zaozhuang & 1.97 & 1.85 & - & - & 0.60 & - & 1.17 & 1.80 & 0.57 & 0.62 & - \\
\hline Xuchang & - & 0.51 & 10.16 & 6.58 & 2.30 & 0.59 & 0.60 & - & - & - & - \\
\hline Zhoukou & 0.67 & 0.96 & 13.23 & 12.49 & 34.14 & 1.71 & 2.38 & 0.88 & 1.20 & - & - \\
\hline Pingdingshan & - & - & 1.70 & 4.18 & 1.14 & 0.52 & - & - & - & - & - \\
\hline Kaifeng & 0.52 & 0.82 & 2.91 & 1.10 & 1.11 & - & - & - & - & - & - \\
\hline Zhengzhou & 0.73 & 1.01 & 4.02 & 2.53 & 1.76 & 0.52 & 0.72 & - & - & - & - \\
\hline Luohe & - & - & 3.23 & 39.61 & 1.96 & 0.53 & - & - & - & - & - \\
\hline Zhumadian & - & - & 2.22 & 26.33 & 4.47 & 3.31 & 0.96 & - & 0.72 & - & - \\
\hline Haozhou & 0.53 & 0.81 & 1.15 & 0.94 & 5.01 & - & 3.42 & 1.04 & 1.02 & - & - \\
\hline Fuyang & - & - & 0.81 & 1.36 & 5.86 & 1.44 & 7.02 & 3.05 & 4.43 & 0.58 & - \\
\hline Xinyang & - & - & 0.71 & 2.40 & 1.86 & 19.25 & 0.79 & - & 0.74 & - & - \\
\hline Suzhou & 0.53 & 0.64 & - & - & 1.18 & - & 11.61 & 10.57 & 2.30 & 1.12 & - \\
\hline Bengbu & - & - & - & - & 0.56 & - & 3.76 & 4.97 & 5.46 & 1.93 & - \\
\hline Huaibei & - & - & - & - & 0.61 & - & 2.79 & 2.28 & 0.68 & - & - \\
\hline Xuzhou & 2.09 & 2.36 & 0.76 & 0.76 & 1.80 & - & 5.83 & 13.35 & 2.31 & 2.32 & - \\
\hline Suqian & - & - & - & - & - & - & 1.21 & 5.17 & 0.79 & 2.57 & - \\
\hline Luan & - & - & - & - & 0.73 & 0.65 & 1.34 & 0.71 & 3.79 & 0.56 & - \\
\hline Yangzhou & - & - & - & - & - & - & 0.68 & 1.08 & 0.81 & 3.92 & 0.77 \\
\hline Huaiyang & - & - & - & - & - & - & 0.87 & 2.28 & 0.74 & 5.88 & 1.43 \\
\hline Taizhou & - & - & - & - & - & - & 0.51 & 0.78 & 0.57 & 2.15 & 1.01 \\
\hline Yancheng & - & - & - & - & - & - & 0.78 & 1.17 & 0.65 & 2.55 & 13.68 \\
\hline Huainan & - & - & - & - & 0.53 & - & 3.14 & 1.46 & 44.33 & 0.75 & - \\
\hline Lianyungang & - & - & - & - & - & - & - & 0.96 & - & 0.91 & 0.95 \\
\hline
\end{tabular}


Table 3

Maximum, minimum, and average distances of economic relationships in the "extremely strong" level.

\begin{tabular}{ll}
\hline Unit: $\mathrm{km}$ & Average distance of economic relationships \\
\hline Minimum & 20.79 \\
Maximum & 78.10 \\
Average & 48.24 \\
\hline
\end{tabular}

flows (i.e., energy or matter) and information theory called ascendancy; he also used network analysis to investigate mixed trophic levels and relational interactions between components [44]. Patten [45] and colleagues developed a branch of ecological network analysis called Environ Network Analysis (ENA), and analyzed indirect effects [46], network amplification [47], network homogenization $[47,48]$, and network synergism [45,49] applying this method. The ecological network analysis research bifurcated into two selfsimilar, yet independent sub-areas, environ analysis and ascendancy analysis [50], both capable of quantifying direct and indirect ecological relationships within the ecosystem.

The two methods mentioned above construct the theoretical underpinning of ENA, and the related analysis methods and indices have been addressed explicitly [42,44,50-54], including network structural analysis and functional analysis (throughflow analysis, utility analysis, control analysis, information-theoretical analysis etc.). The methods and indices derived from ENA are listed in Table 1.

These methods and concepts composing ENA have not only been widely used in the study of specific ecosystems, but also extended into other realms, such as social and economic systems
$[52,53]$. ENA has proved an effective and explicit technique for analyzing the structural and functional properties of the system as a whole [55-60], thus may reflect the changed condition of the environment by human disturbance.

The methodology for network utility analysis is described in following literatures $[45,49,53]$, which gives us a direct net flow matrix $D=D(F)$ based on the steady net flows between compartments normalized by the compartmental throughflow such that $d_{i j}=\frac{f_{i j}-f_{j i}}{T_{i}}(j, i=1, \ldots n)$. In addition to the direct relations proceed directly between two compartments. The integral utility matrix $U$, which describes the contribution of all direct and indirect relations, is found by summing all powers of $D$ :

$U(F)=\sum_{m=0}^{\infty} D(F)^{m}=(\mathrm{I}-D(F))^{-1}$

The result is useful because the signs of $\mathbf{U}$ provide the integral relations between network nodes (which may vary from the direct relations) and the overall sign comparisons classify the network according to the degree of mutualism. We calculate a utility function $J(F)$ as a share of positive relations in $\operatorname{sign}(\mathbf{U})$.

$J(F)=\frac{S_{+}(F)}{S_{-}(F)}$

where $S_{+}(F)$ is the number of all positive relations, and $S_{-}(F)$ is all negative relations in matrix $U(F)[61]$. Thus, $J(F)$ characterizes the ratio between the number of all positive and all negative relations. We consider $J(F)$ as a goal function related to network mutualism in the energy system [49]. When $\mathrm{J}(\mathrm{F})>1$ mutualism occurs, indicating

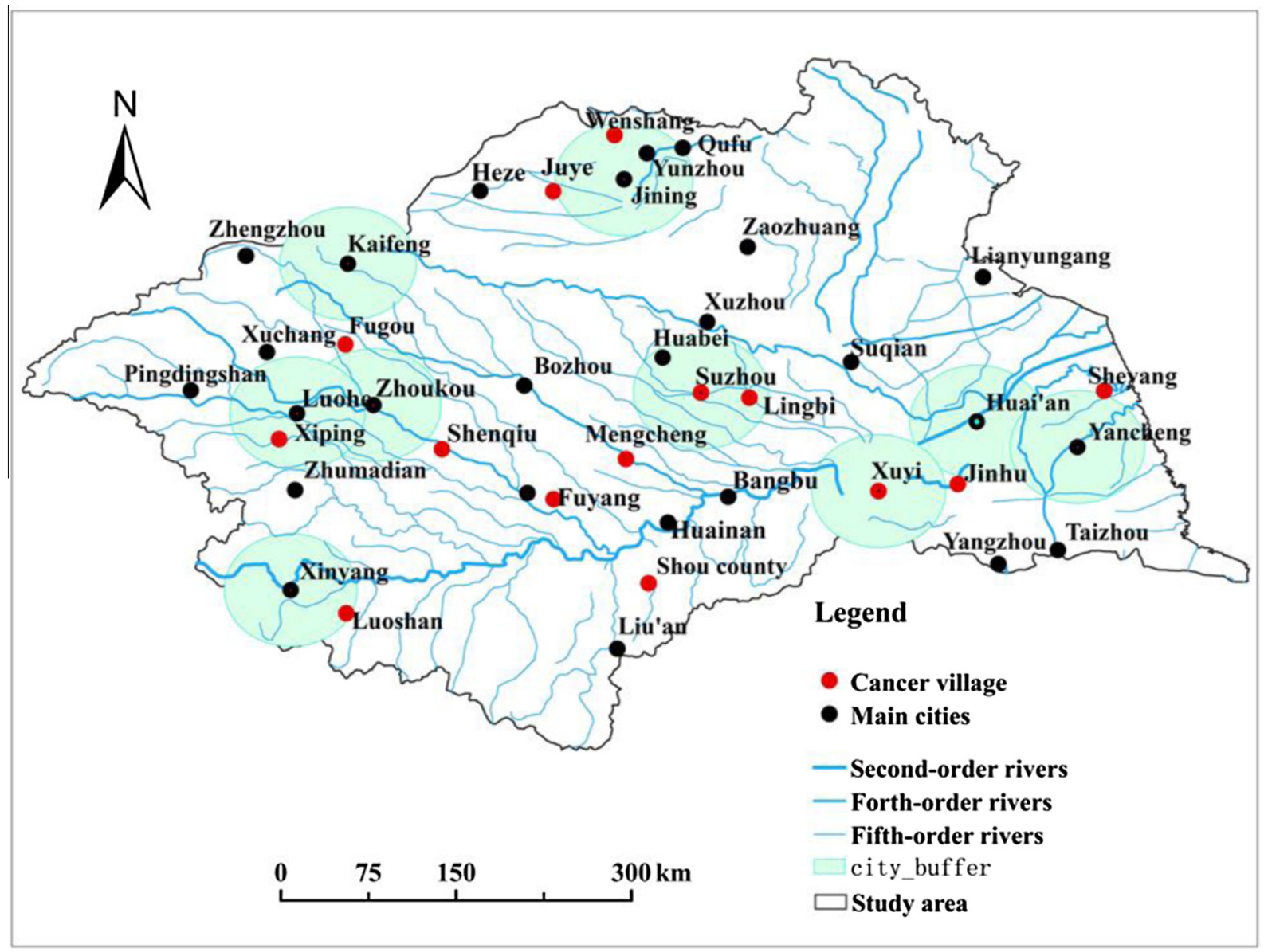

Fig. 5. Influence range of big cities (radius $=48.24 \mathrm{~km}$ ) 
that the system overall has more positive sign-pair relations than negative ones.

\section{Results}

\subsection{The economic relationship between cancer villages and adjacent} cities

From pollution data, economic data, and the above calculation procedures, we obtained the economic relationships between 12 high-risk areas of cancer along the Huaihe River, the economic relationships between high-risk areas of cancer and large- and medium-sized cities near the Huaihe River, and the year 2010 matrix of the economic relationship $R_{i j}$ (see Table $1 \mathrm{~A}$ in Appendix). Although the number of cancer villages in the Huaihe River Basin is 14 , only 12 will be discussed when analyzing the economic relationships between them and adjacent cities because the Yongqiao and Yingdong areas lack economic data, and Jinhu County lacks pollution data. GIS visualization technology was adopted to generate a distribution diagram of the remaining 12 high-risk cancer areas and the adjacent urban economic relationships (see Figs. 24 ). The economic relationship is defined as follows: $R_{i j} \geqslant 10$ stands for "extremely strong", $5 \leqslant R_{i j} \leqslant 10$ stands for "strong", $0.5 \leqslant R_{i j}$ $\leqslant 5$ stands for "weak", and $R_{i j}<0.5$ is negligible. This self-defined classification method was used to divide the different levels.

As it can be seen in Figs. 2-4, the differentiation of economic relationships across space is evident, and the degree of economic relationships varies significantly. The influence intensity of the cities near the high-risk cancer areas is in close correlation with distance and urban scale (economic development level and population). One high-risk cancer area may be affected by the influence from more than one adjacent city (see Table 1A in Appendix). For example, Juye County in Shandong Province is highly affected by the economic influence of Jining and Heze, quantified around 32.39 and 11.45 units respectively (unit = one hundred million $\mathrm{RMB} \times$ ten thousand people $/ \mathrm{km}^{2}$ ). Xiping County in Henan Province, as a more typical example, is surrounded by three cities (Luohe, Zhoukou, and Zhumadian). Its economic influence also fully embodies the cities' influence on cancer villages: the economic relationships of Xiping with these three cities are 39.61, 12.49, and 39.61 units, respectively (see Table 1). Simply put, a high-risk cancer area can be affected from several adjacent cities. Moreover, a large city may also emit influence to a number of cancer areas, for instance, Suzhou in Anhui Province economically affects two cancer areas: Lingbi County and Mengcheng County. Similarly, Jining also exerts effects on the cancer villages in Wenshang County and Juye County. From the distribution diagram, we can clearly see that the distance from Jining to Wenshang and the distance from Jining to Juye is the same, similar to the distance from Suzhou to Lingbi and Suzhou to Mengcheng. Through concrete data comparison, the distance from Jining to Wenshang and the distance from Jining to Juye is 36.48 and $44.73 \mathrm{~km}$, respectively; the distance from Suzhou to Lingbi and the distance from Suzhou to Mengcheng is 56.25 and $56.35 \mathrm{~km}$, respectively. Thus, we can further hypothesize that a big city's impact on adjacent small cities and even counties can be represented by a circle with

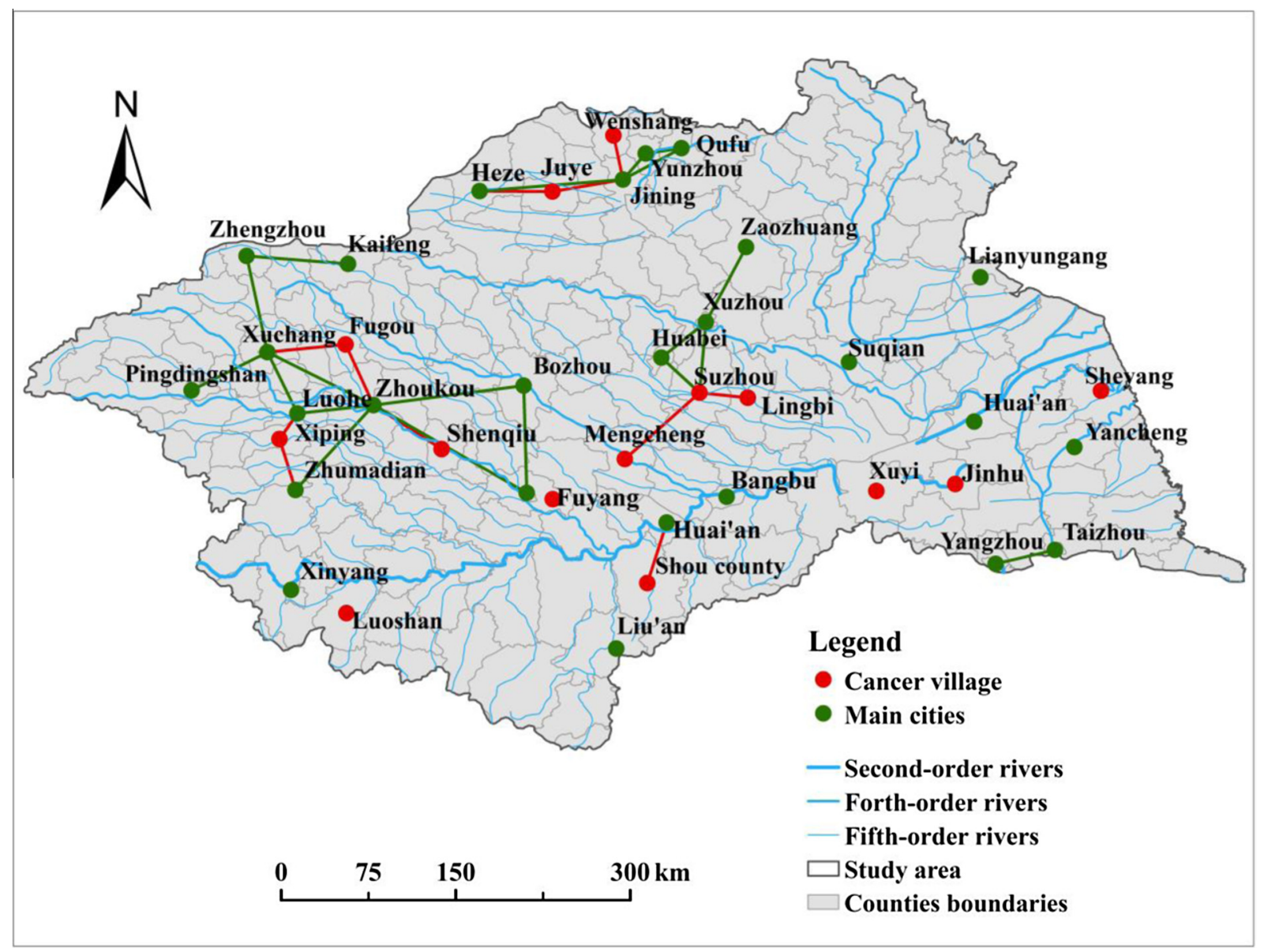

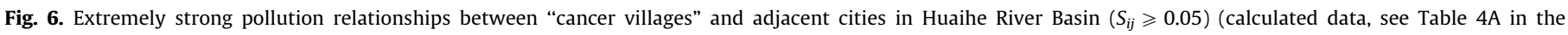
Appendix). 


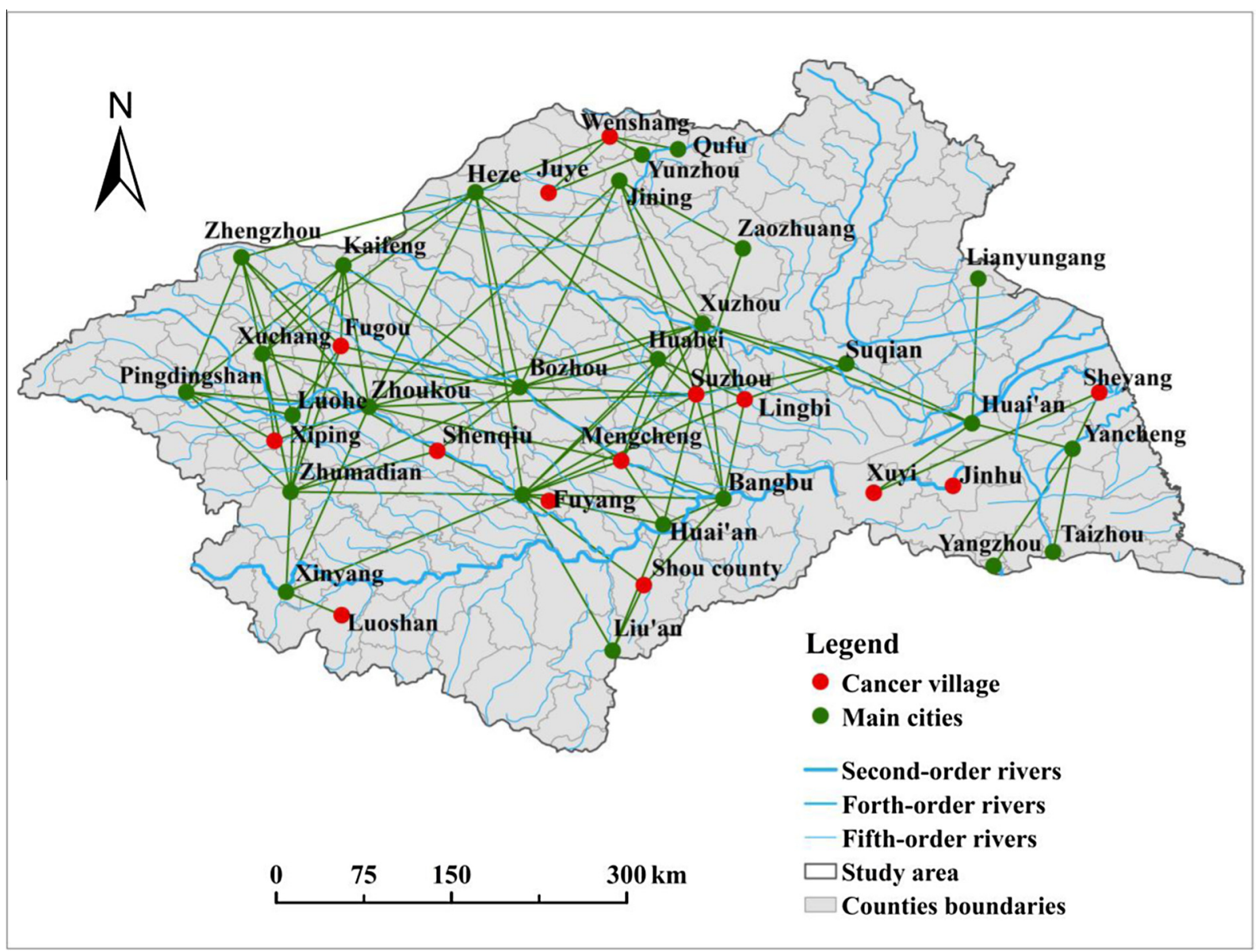

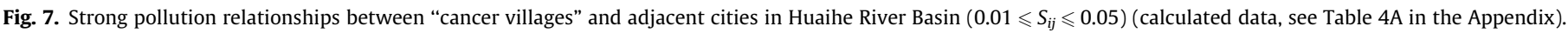

a certain radius expressing its economic and environmental influence. This is confirmed by the case of three cancer villages in the economic radiation area of Zhoukou in Henan Province (Fugou County, Xiping County, and Shenqiu County) among which Shenqiu has received much media attention. The distances from Zhoukou to Fugou County, Xiping County, and Shenqiu County are $55.78,68.08$, and $44.41 \mathrm{~km}$, respectively (see Table 2), with an average distance of $56.09 \mathrm{~km}$. The economic relationships are $13.22,13.22$, and 12.49 units, which conforms to the "extremely strong" scope of economic relationships described above.

According to these results, the maximum, minimum, and average distance of economic relationships in the "extremely strong" level were measured in this study. Circles were drawn with major cities at the center and $48.24 \mathrm{~km}$ as the radius on the map of the Huaihe River Basin, as shown in Table 3 and Fig. 5. It is found that almost all cancer villages are included in the circles. Thus, villages and counties within the distance of $48.24 \mathrm{~km}$ from big cities are significantly affected.

Regarding the economic relationships between each pair of cities, the nearer the two cities are, the larger the economic value, population, and economic relationships. Thus, they have a closer economic relationship. For instance, Jining in Shandong Province exerts the greatest economic influence on the two monitored counties because it has the largest population and economic performance. On the other hand, though Qu Fu and Yanzhou are separated by the same distance as Jining to Wenshang, the two cities are less developed than Jining and hence have no such intense exertion as Jining to the adjacent smaller cities or counties. Furthermore, the reason why the economic relationship between of Heze and Wenshang significantly differs from the one with Juye is that the two monitored counties differ in their distance to Heze: the distance from Heze to Juye is one-half that from Heze to Wenshang. Therefore, the economic radiation of Heze to Juye is "extremely strong", while its radiation to Wenshang is "weak". The economic relationship performance score of Juye is three times as large as that of Wenshang (see Appendix Table 1A).

Through the analysis of the data in Tables 2A and 3A of Appendix, we found that there are 14 high-risk cancer areas and counties. Excluding the Yingdong and Yongqiao areas that lack sufficient economic and population data, about $81.8 \%$ of the remaining 10 areas and counties of cancer influence within $50 \mathrm{~km}$ of adjacent cities have economic relationships characterized as "extremely strong".

\subsection{The pollution relationship between cancer villages and adjacent} cities

Based on the cancer villages' economic relationships with adjacent cities, we hypothesized that the reason why malignant tumor diseases happen frequently may be strictly correlated to the pollution of the adjacent environment because environment pollution can spread to these areas and counties through the air, soil, and surface water. This leads to accumulation of the pollutants, resulting in higher cancer incidence. We calculated the pollution relationships between high-risk areas of cancer and large- and medium-sized cities near the Huaihe River and the year 2005 matrix of the economic relationship $S_{i j}$ (see Table $4 \mathrm{~A}$ in Appendix). The pollution relationship is defined as follows: $S_{i j} \geqslant 0.05$ stands 
for "extremely strong", $0.01 \leqslant S_{i j} \leqslant 0.05$ stands for "strong", $0.005 \leqslant S_{i j} \leqslant 0.01$ stands for "weak", and $S_{i j}<0.005$ is negligible.

As can be seen from Figs. 6-8 and Table 4A in Appendix, the pollution relationships of high-risk cancer areas to adjacent cities vary significantly. The closer two cities are, the stronger pollution relationships exist. For example, the distance between Xuchang and Fugou is $\sim 50 \mathrm{~km}$, with a pollution relationship $>0.05$ ("extremely strong"). Thus, distance exerts an important influence on the intensity of pollution relationships, and only sufficiently close cities have close direct pollution relationships. Cities with a higher degree of pollution tend to greatly affect the adjacent cities, such as Xuchang's and Zhoukou's pollution influencing Fugou. The pollution degree in Xuchang is 0.61 and in Zhoukou is 1.00. With the same distance to Fugou, the pollution radiation of Xuchang to Fugou is 0.05 and that of Zhoukou to Fugou is 0.08. Therefore, cities with a higher degree of pollution are more likely to generate a larger pollution radiation to adjacent cities.

According to this analysis, we can see that areas and counties with a distance of $<50 \mathrm{~km}$ from big cities tend to be greatly influenced by the city economy. Applying this conclusion to pollution relationships (i.e., comparing the distance between cancer villages (see Table 2A in Appendix) and the adjacent cities with the data of "extremely strong" pollution relationships (see Table 5A in Appendix)), we sought to determine if the scope of the "extremely strong" pollution relationship was still the about $50 \mathrm{~km}$ identified for economic relationships. Results indicates that $63.6 \%$ of big cities reach an "extremely strong" degree of pollution relations with a distance of $50 \mathrm{~km}$ from the 10 high-risk cancer counties. Table 3 shows the pollution relationship matrix of 38 cities and counties by means of the gravity model. We expanded the range from big cities to analyze and select the most appropriate distance when considering pollution relationships.

The maximum, minimum, and average distance of "extremely strong" pollution relationships was measured. Compared to Table 3 , we found that the difference between maximum and minimum distances characterized by "extremely strong" pollution relationships is smaller than the difference between maximum and minimum distances characterized by "extremely strong" economic relationships, as is the average distance. This phenomenon is likely due to the fact that pollution degree data are much scarcer than economic strength values, thus generating rather smaller values when calculating the pollution relationships. To conclude, within the same distance, the number of "extremely strong" economic relationship cancer villages is greater than the number of "extremely strong" pollution economic relationship of cancer villages.

In addition, Figs. 6-8 also indicates that there is no large-scale city around Xuyin County and Jinhu County. The nearest big city to Xuyin County is Huaian, with a distance of $72.73 \mathrm{~km}$; the distance from Huaian to Jinhu County is $65.12 \mathrm{~km}$. Further, the economic scale and population is not very large in Huaian, and its pollution is not serious (pollution level $=0.39$ ). On the map, however, river systems are widely distributed near Xuyin County and Jinhu County. Jinhu County is surrounded by Baimahu Lake, Baoyinghu Lake, and Gaoyouhu Lake, with the Huaihe River flowing through the area. Hongzehu Lake lies to the east and north of Xuyin County, with the Huaihe River flowing through the area. Therefore, aside from the causes of higher incidence of cancer, as well as its polluted environment, we should also take into consideration the

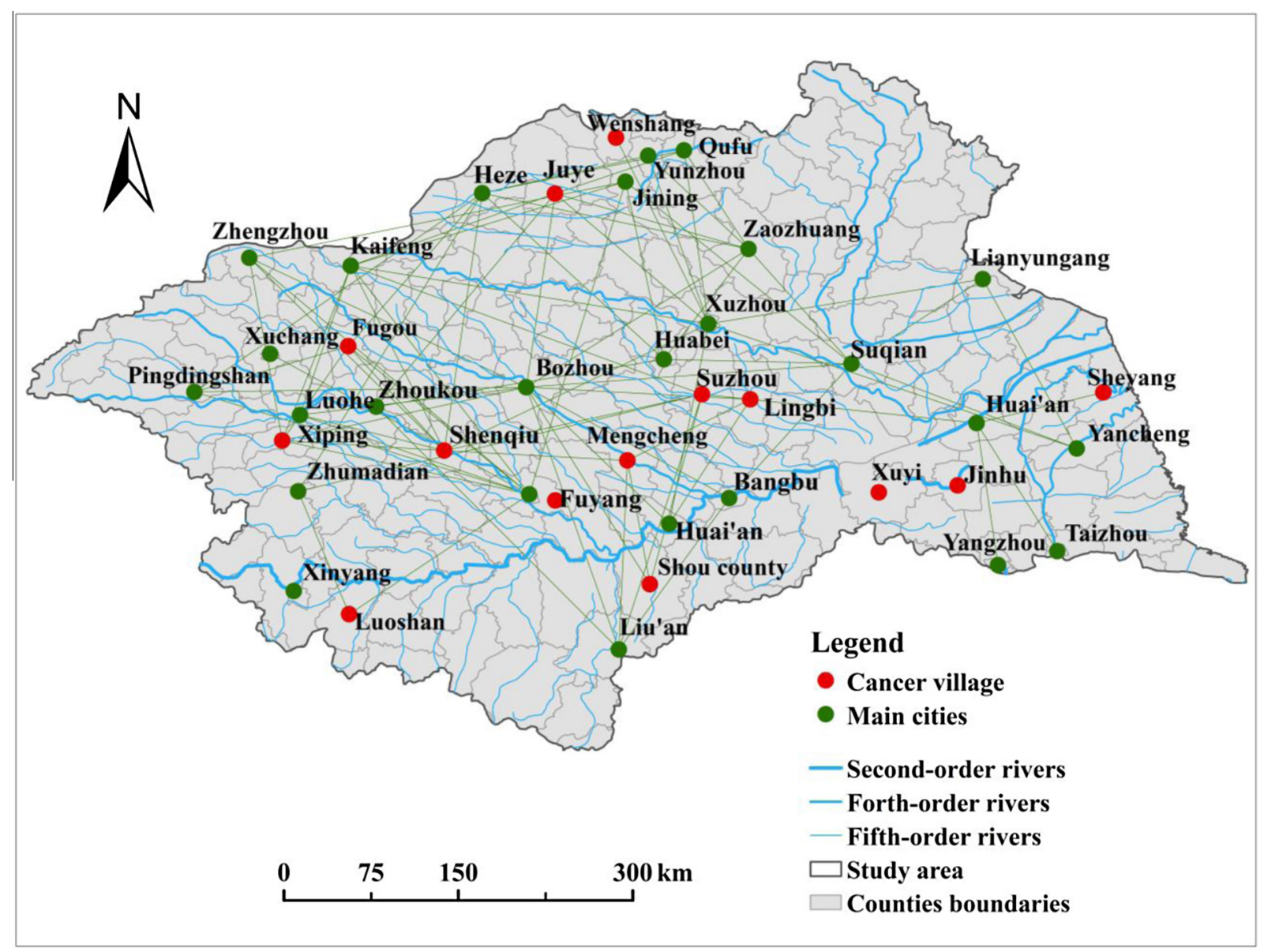

Fig. 8. Weak pollution relationships between "cancer villages" and adjacent cities in Huaihe River Basin $\left(S_{i j}<0.005\right)($ calculated data, see Table $4 \mathrm{~A}$ in the Appendix). 
rich water resources in these counties with more possibility of serious water pollution than other counties. Once the Huaihe River and its tributaries are contaminated, they will pose a threat to the drinking water of the two counties and cause a higher incidence of malignant tumors.

\subsection{The relationship between cancer villages and rivers}

A buffer zone with a radius of 3,5 , or $10 \mathrm{~km}$ in rivers on and above the national fifth level in the Huaihe River Basin was drawn. An intersection tool was used to calculate the area of the 14 cancer villages falling within the buffer zone, and its percentage of the total area of the county was calculated. In Fig. 9, the results demonstrate that the 14 cancer villages falling within the $3-\mathrm{km}$ buffer zone account for $20 \%$ of the total, those within the $5-\mathrm{km}$ buffer zone account for $50 \%$, and those within the $10-\mathrm{km}$ buffer zone account for $>80 \%$. Although there are a few rivers above the fifth level in Wenshang County and the area located in the buffer zone is relatively small, its area reaches $30 \%$. In the 10 -km buffer zone, Xuyi County and Jinhai County are among the highest proportion (95.8\% and $89.9 \%$ respectively), which is related to their geographical positions. As with the analysis above, there are numerous drainage sources near Xuyi County and Jinhai County, and therefore, they tend to present a higher area proportion within the $10-\mathrm{km}$ buffer zone. About $80 \%$ of the cancer villages' area falls within the $10-\mathrm{km}$ buffer zone indicating that the distribution of cancer villages is closely related to the distribution of rivers.

In addition, according to pollution data in various counties along the Huaihe River, we found that cities in the midstream and downstream portions of the Huaihe River are more seriously contaminated than those upstream, and that there are more cancer villages in the midstream and downstream portions than upstream. Therefore, we inferred that this may due to the fact that industrial pollution emissions increase with the development of the cities, and cause river pollution and environmental and human health impacts. Pollutants will constantly flow with the river to low-lying areas and do larger harm to the health of the people in such areas (i.e., midstream and downstream). There are 10 cancer villages in the midstream and downstream portions of the Huaihe River (Wenshang, Juye, Mengcheng Shouxian, Lingbi, Yongqiao, Yingdong, Xuyi, Sheyang, and Jinhu), while there are four cancer villages upstream (Fugou, Xiping, Shenqiu, and Luoshan). Rivers, therefore, seem closely related to the distribution of cancer villages, and it is more likely for malignant tumor diseases to occur in the midstream and downstream portions.

\subsection{Economic utility analysis}

With the help of a utility relation table, we determined the direct and indirect relationships between cancer villages and their

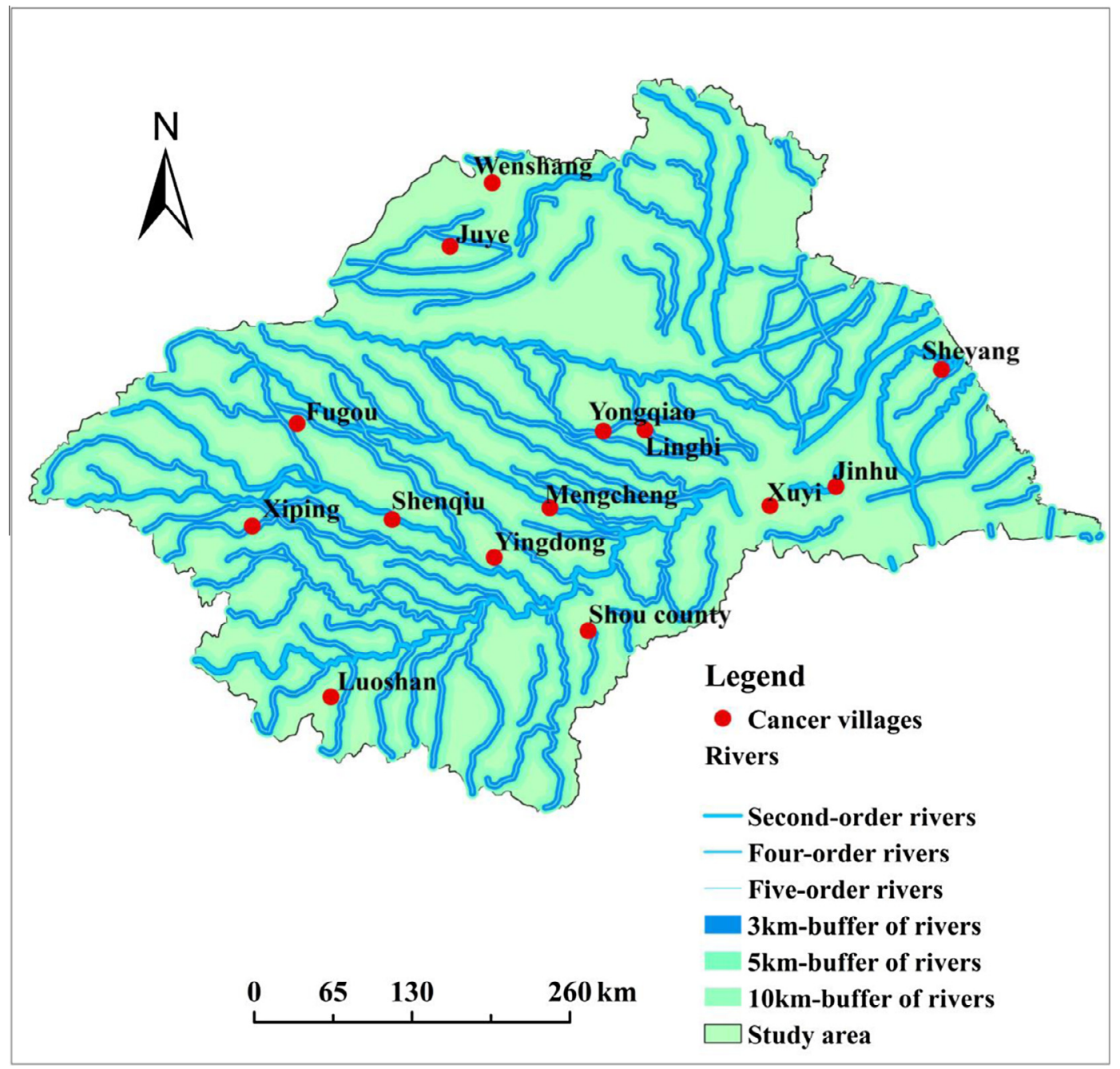

Fig. 9. About $80 \%$ of the cancer villages' area falls within the $10-\mathrm{km}$ buffer zone. 
adjacent cities. In biology, direct interactions over conservative resources (energy, nutrients, water, etc.) are zero-sum, meaning they are either $(+,-),(-,+)$ or $(0,0)$. The first two represent transfer from one (whichever has the minus) to the other (whichever has the plus), and the last represent neutralism where the two do not directly interact. Out of these direct interactions emerge indirect and integral relations, which can still include $(+,-)$, $(-,+)$ and also $(+,+),(-,-)$, representing mutualism and competition, respectively. Systems are well connected enough that null or zero relations are not exhibited. Although this definition is mainly used for species, it appears it can be used to describe the relationship among cities, and political, social, or economic exchanges between individuals and groups as well. Thus, as long as the premise of interaction exists, there are gains and losses of interests of the related participants.

With general flow matrix $F$, we established a direct utility matrix $D$ (see Table 6A in Appendix, and Fig. 10) and Sgn $(D)$ matrix (see Fig. 11) and compared the direct relationship between any two nodes across the main diagonal of the matrix. For example, $(\operatorname{sd}(12,1), \operatorname{sd}(1,12))=(-,+)$ indicates an "exploited relationship". So Wenshang's economy is exploited by Jining. In addition, in Fig. 10, one can observe that the economic relationships indicate that all big cities affect cancer villages, while counties have no con- tribution to the economy in big cities. There are direct economic relationships between cities and counties, as well as between counties. For example, $(\operatorname{sd}(6,1), \operatorname{sd}(1,6))=(+,-)$ shows that there is a direct economic relation between Luoshan County and Wenshang and that Luoshan plunders Wenshang's economy. The SD matrix has the same number of plus and minus signs because all of the nodes are either inputs or outputs.

Fig. 11 shows the integral utility matrix $\operatorname{Sgn}(U)-$ from Eq. (1), in which the dark red element is a "+" relationship, while the light red element is the "-" relationships. The results show that there are some differences in matrix $U$. Only several counties' elements add up to zero in the general matrix, and the rest in the $U$ matrix are not zero, indicating that all nodes have direct or indirect relationships with each other. Second, when some nodes' relationship changes, the entire network change must be considered. For example, $(\mathrm{su}(17,1)$, su $(1,17))=(+,-)$ indicates an "exploitation relationship." So Xuchang needs to indirectly obtain economic support from Wenshang. However, in the Sgn $(D)$ matrix, (sd (17, $1)$, sd $(1,17)=(0,0)$. This shows us that there is a "neutral relationship" between Xuchang and Wenshang, i.e., there is no direct linkage transfer the two. $(\mathrm{su}(18,4)$, su $(4,18)=(+,+)$ shows there is a mutualism between Zhoukou and Xiping, i.e., they are mutually beneficial in development. However, in the Sgn $(D)$ matrix, their

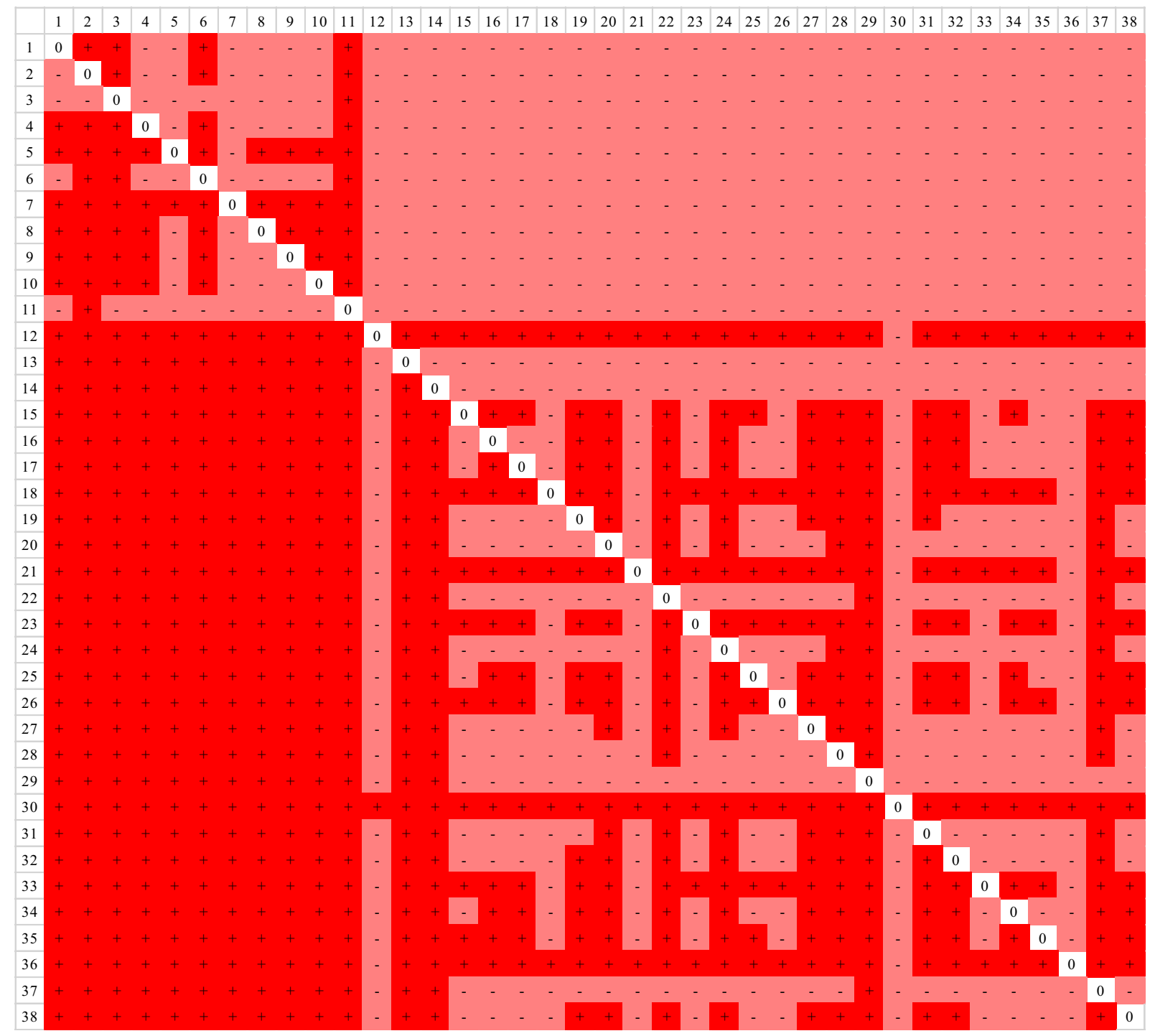

Fig. 10. Direct economic connection matrix sgn(D). 


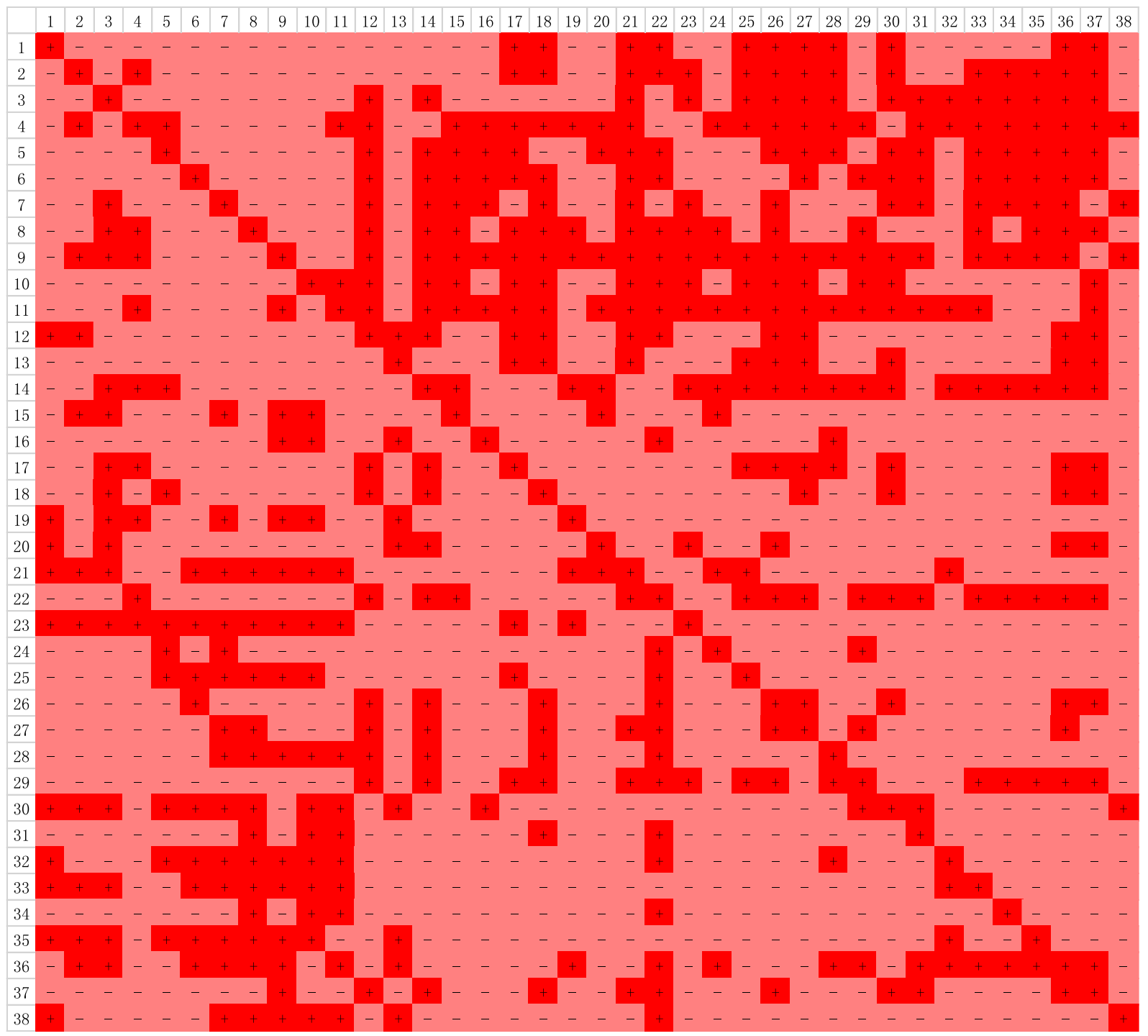

Fig. 11. Integral utility matrix $\operatorname{sgn}(U)$.

direct relationship reflects an "exploitation relationship": Zhoukou presents economic output to Xiping. In conclusion, in the entire network system of the Huaihe River, the economic relationships between cities and counties are not limited to one dimension; they can constitute two-dimensional networks and generate secondary relationship through the relationships between networks. Third, the utility function is no longer zero-sum. In the utility matrix $\operatorname{Sgn}(U)$, there are 463 positive and 685 negative values, which indicate that among the economic relationships of the Huaihe River, what they constitute is a comparatively competitive network. Based on Eq. ( 2$), J(F)=463 / 685=0.676$ through the integral utility matrix Sgn $(U)$. The economies of cities and counties are intertwined. Big cities' economies affect the counties', and each element exerts mutual influence on the others.

\subsection{Pollution utility analysis}

Similar to the economic utility analysis, through a flux matrix $\mathrm{F}$, we established a direct flow matrix $D$ (see Table 7A in Appendix and Fig. 12) and matrix $\operatorname{Sgn}(D)$ (see Fig. 13). The direct relationship between any two nodes can be compared across a diagonal line. Unlike economic relations, the direct pollution linkage between cancer villages and their adjacent cities is a mutually affected rela- tionship, rather than a one-way impact of big cities on counties. For example, $(\operatorname{sd}(12,1), \operatorname{sd}(1,12))=(-,+)$ indicates an "exploited relationship," and $(\operatorname{sd}(22,5), \operatorname{sd}(5,2))=(+,-) ;(\operatorname{sd}(6,4) \operatorname{sd}(4,6))=(0,0)$ shows a "neutral relationship." In other words, Wenshang's pollution is affected by Jining and Luoshan's by Shenqiu, but there is no direct pollution interaction between Xiping and Luoshan. As shown in Table 4, as a source of pollution, Wenshang, Juye, Fugou, and Mengcheng transfer pollution to other counties and cities, reducing their own pollution degree. Different from direct economic relationships, direct pollution relationships show that cities can influence the cancer villages and vice versa. Also, through the analysis of the Sgn $(D)$ matrix of cancer villages and their adjacent cities, we found that the known cancer villages are affected by the pollution output of adjacent cities (see Table 5). Likewise, the SD matrix has the same number of pluses and minuses because all of the nodes are either inputs or outputs of conservation (or 0 ). Based on Eq. (2), $J(F)=640 / 730=0.877$ through the integral utility matrix $\operatorname{Sgn}(U)$.

Fig. 13 shows the integral utility matrix $\operatorname{Sgn}(U)$, in which the dark blue element is a "+" relationship, while light blue element is a "-" relationship. The results also show that there are some differences in matrix $U$. First, all of the elements in $U$ matrix are non-zero, which shows that all nodes produce direct or indirect 


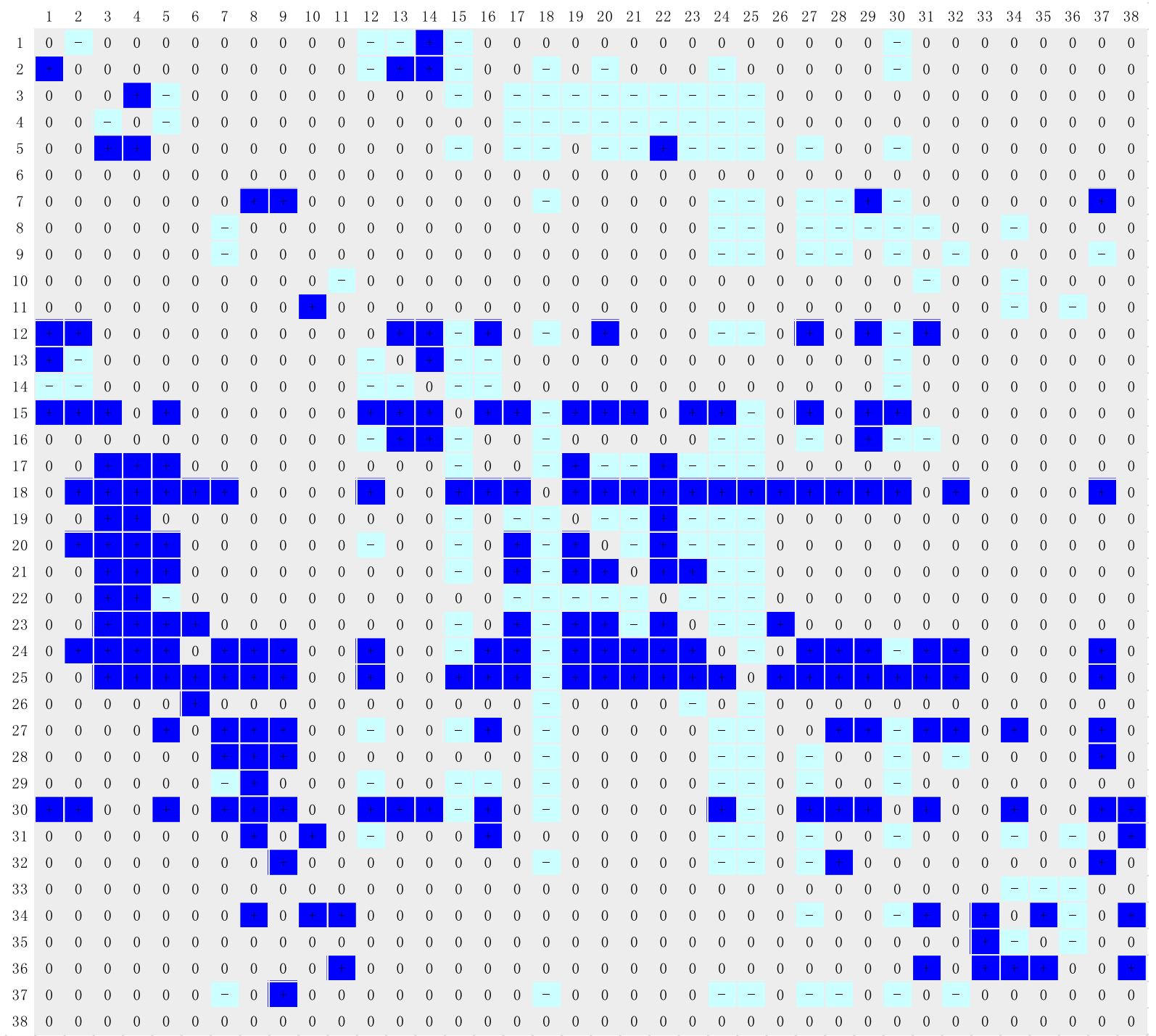

Fig. 12. Direct pollution connection matrix $\operatorname{sgn}(\mathrm{D})$.

relationships with one another. Second, when a node's relationship changes, the entire network change must be considered, as with the previous case about economic influence. For example, (su $(22,5)$, su $(5,22))=(-,-)$ indicates a competitive relationship. Considering the indirect relationship between Luohe and Shenqiu, the two maintain a competitive relationship and are both affected by other cities' or counties' pollution. There is a competitive relationship in "receiving" pollution between Luohe and Shenqiu, which means if one city receives more pollution from outside, the other will receive less. It can be seen that big cities can influence cancer villages, while highly polluted counties like Shen Qiu can also affect big cities. Moreover, (su $(18,7)$, su $(7,18)=(+,+)$ shows that there is a mutualism between Zhoukou and Mengcheng; the pollution migration actually aggravates the pollution degree in both places taking indirect influence into accountant. Therefore, it is very likely that some industrial chains exist in both of these locations that connect the pollution emissions. Further, (sd $(18,7), \operatorname{sd}(7,18))=(-,+)$ reflects that their direct relationship is an "exploitation relationship": Mengcheng absorbs pollutants from Zhoukou, decreases Zhoukou's pollution level. Mere concern for direct relationships will lead to ignorance of the source and convergence of pollution. Take Table 5 for example: the fact of cancer villages acting as the source of pollution increases when considering indirect pollution. Meanwhile, more cancer villages in turn become pollution impact providers, affecting additional cities and counties. Likewise, in $\operatorname{Sgn}(D),(\operatorname{sd}(3,1), \operatorname{sd}(1,3))=(0,0)$ shows that there is no direct pollution relationship between Fugou and Wenshang, but in $\operatorname{Sgn}(U),(\operatorname{su}(3,1) \operatorname{su}(1,3))=(+,-)$ indicates an indirect pollution relationship in which Fugou receives pollution from Wenshang. We found that seriously polluted cancer villages can increase pollution in adjacent cities and counties rather than act as mere "receivers" of pollution. Third, the utility function is no longer zero-sum. In the utility matrix Sgn $(U)$, there are 640 positives and 730 negatives, indicating that from the point of view of pollution relationships along the Huaihe River, cancer villages and adjacent cities constitute a competitive network: the pollution in cities and counties are mutually influenced. Fourth, after considering the indirect relationships in the network, more "mutualistic" and "competitive" relationships appear (see Tables 6 and 7). Sixty-three $(+,+)$ mutualism examples exist in indirect relationships, showing that both cities are seriously contaminated through transferring pollution to the other one. There are 98 pairs of $(-,-)$ competitive relationships in which both cities decrease their pollutant concentration by transferring pollution to the other. Therefore, 


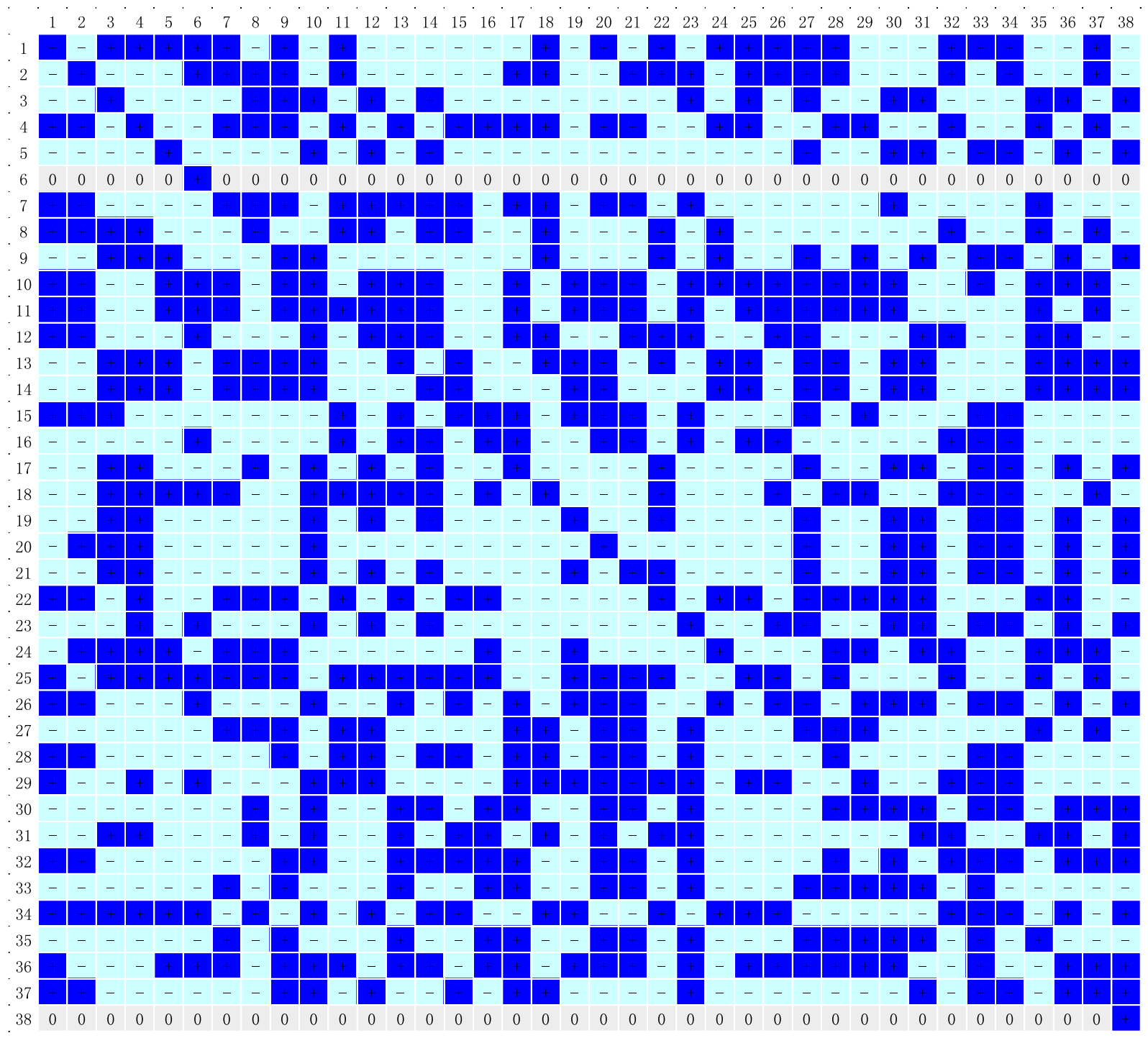

Fig. 13. Integral utility matrix $\operatorname{sgn}(U)$.

Table 4

Maximum, minimum, and average distance of pollution relationships in the "extremely strong" level.

\begin{tabular}{ll}
\hline Unit: $\mathrm{km}$ & Average distance of pollution relationships \\
\hline Minimum & 20.79 \\
Maximum & 58.63 \\
Average & 44.27 \\
\hline
\end{tabular}

Table 5

The direct pollution interaction between cancer villages and big cities.

\begin{tabular}{lll}
\hline Cancer village & Source of pollution & Direct pollution interaction \\
\hline Wenshang & Yanzhou & $(+,-)$ \\
Juye & Qufu & $(+,-)$ \\
Juye & Yanzhou & $(+,-)$ \\
Fugou & Xiping & $(+,-)$ \\
Mengcheng & Lingbi & $(+,-)$ \\
Mengcheng & Shou & $(+,-)$ \\
Mengcheng & Huaibei & $(+,-)$ \\
Mengcheng & Huainan & $(+,-)$ \\
\hline
\end{tabular}

for the 63 pairs of mutually affected cities and counties, they can invite trouble when transferring pollutants to other cities and counties (see Table 8).

Table 6

The list of cancer villages which are affected indirectly by surrounding cities.

\begin{tabular}{|c|c|}
\hline $\begin{array}{l}\text { Cancer } \\
\text { village }\end{array}$ & Indirect pollution sources \\
\hline Wenshang & $\begin{array}{l}\text { Fugou, Shenqiu, Shou, Zhoukou, Kaifeng, Haozhou, Suzhou, } \\
\text { Yangzhou }\end{array}$ \\
\hline Juye & Shou, Xuchang, Zhoukou, Zhumadian, Fuyang, Suzhou \\
\hline Fugou & Xuyi, Jining, Zhumadian, Suzhou, Xuzhou, Taizhou \\
\hline Xiping & $\begin{array}{l}\text { Mengcheng, Sheyang, Heze, Zaozhuang, Bengbu, Lu'an, Taizhou, } \\
\text { Huainan }\end{array}$ \\
\hline Shenqiu & Jining, Suzhou, Xuzhou, Suqian, Yangzhou, Huainan \\
\hline Mengcheng & $\begin{array}{l}\text { Lingbi, Shou, Jining, Heze, Xuchang, Kaifeng, Zhengzhou, } \\
\text { Zhumadian, Xuzhou }\end{array}$ \\
\hline Lingbi & Sheyang, Jining, Heze, Zhoukou, Lu'an, Taizhou, Huainan \\
\hline Shou & Huaibei, Suqian, Huaian \\
\hline Xuyi & Haozhou, Fuyang, Suzhou, Bengbu, Yangzhou, Taizhou \\
\hline Sheyang & $\begin{array}{l}\text { Jining, Qufu, Yunzhou, Xuchang, Pingdingshan, Kaifeng, } \\
\text { Zhengzhou, Zhumadian, Haozhou, Xinyang, Xuzhou, Yangzhou, } \\
\text { Taizhou, Huainan }\end{array}$ \\
\hline
\end{tabular}


Table 7

63 pairs of $(+,+)$ mutualism examples exist in indirect relationships.

\begin{tabular}{|c|c|}
\hline $\begin{array}{l}\text { Cancer } \\
\text { village }\end{array}$ & Indirect pollution sources \\
\hline Wenshang & $\begin{array}{l}\text { Xiping, Sheyang, Fuyang, Xinyang, Bengbu, Lu'an, Huaian, } \\
\text { Huainan }\end{array}$ \\
\hline Juye & $\begin{array}{l}\text { Mengcheng, Lingbi, Sheyang, Luohe, Xinyang, Bengbu, Lu'an, } \\
\text { Huainan }\end{array}$ \\
\hline Fugou & Lingbi, Shou, Yunzhou, Fuyang, Suqian \\
\hline Xiping & $\begin{array}{l}\text { Wenshang, Lingbi, Shou, Qufu, Xuchang, Zhoukou, Kaifeng, } \\
\text { Zhengzhou, Haozhou, Fuyang, Huaibei }\end{array}$ \\
\hline Shenqiu & Yunzhou, Huaian, Yancheng \\
\hline Mengcheng & Juye, Qufu, Yunzhou, Zhoukou, Taizhou \\
\hline Lingbi & Juye, Fugou, Xiping, Yunzhou, Luohe, Haozhou \\
\hline Shou & Fugou, Xiping, Luohe, Haozhou, Suzhou, Yangzhou, Yancheng \\
\hline Xuyi & $\begin{array}{l}\text { Jining, Qufu, Yunzhou, Xuchang, Pingdingshan, Kaifeng, } \\
\text { Zhengzhou, Zhumadian, Xinyang, Huaibei, Xuzhou, Yancheng, } \\
\text { Huainan }\end{array}$ \\
\hline Sheyang & Wenshang, Juye, Fuyang, Suzhou, Bengbu, Huaibei \\
\hline
\end{tabular}

Table 8

98 pairs of $(-,-)$ competitive relationships exist in indirect relationships.

\begin{tabular}{|c|c|}
\hline $\begin{array}{l}\text { Cancer } \\
\text { village }\end{array}$ & Indirect pollution sources \\
\hline Wenshang & $\begin{array}{l}\text { Juye, Qufu, Yunzhou, Zaozhuang, Xuchang, Pingdingshan, } \\
\text { Zhengzhou, Zhumadian, Xuzhou, Suqian, Taizhou }\end{array}$ \\
\hline Juye & $\begin{array}{l}\text { Wenshang, Fugou, Shenqiu, Qufu, Yunzhou, Zaozhuang, } \\
\text { Pingdingshan, Huaibei, Xuzhou, Suqian, Yangzhou, Taizhou, } \\
\text { Yancheng }\end{array}$ \\
\hline Fugou & $\begin{array}{l}\text { Juye, Xiping, Shenqiu, Mengcheng, Sheyang, Zaozhuang, Luohe, } \\
\text { Xinyang, Bengbu, Huaibei, Lu'an, Yangzhou, Huainan }\end{array}$ \\
\hline Xiping & $\begin{array}{l}\text { Fugou, Shenqiu, Xuyi, Jining, Xinyang, Suzhou, Xuzhou, } \\
\text { Yangzhou, Yancheng }\end{array}$ \\
\hline Shenqiu & $\begin{array}{l}\text { Juye, Fugou, Xiping, Mengcheng, Lingbi, Heze, Zaozhuang, } \\
\text { Xuchang, Pingdingshan, Kaifeng, Zhengzhou, Luohe, } \\
\text { Zhumadian, Xinyang, Bengbu, Huaibei, Lu'an, Taizhou, Huainan }\end{array}$ \\
\hline Mengcheng & $\begin{array}{l}\text { Fugou, Shenqiu, Zaozhuang, Pingdingshan, Xinyang, Bengbu, } \\
\text { Huaibei, Xuqian, Lu'an, Huaian, Huainan }\end{array}$ \\
\hline Lingbi & $\begin{array}{l}\text { Shenqiu, Shou, Xuyi, Zaozhuang, Pingdingshan, Kaifeng, } \\
\text { Zhengzhou, Zhumadian, Xinyang, Bengbu, Huaibei, Yangzhou, } \\
\text { Yancheng }\end{array}$ \\
\hline Shou & $\begin{array}{l}\text { Lingbi, Jining, Heze, Zaozhuang, Xuchang, Pingdingshan, } \\
\text { Kaifeng, Zhengzhou, Zhumadian, Xinyang, Xuzhou }\end{array}$ \\
\hline Xuyi & Xiping, Lingbi, Heze, Zaozhuang, Luohe \\
\hline Sheyang & Fugou, Haozhou, Suqian, Lu'an, Yangzhou, Huaian \\
\hline
\end{tabular}

\section{Conclusions}

Because of China's large population size, these Chinese data contribute significantly to the global burden of cancer [33]. Untangling the causal web linking urbanisation and human health needs a multidisciplinary approach, and metrics that capture the multidimensional process of urban-to-urban transformation show promise in the assessment of longitudinal changes in urbanicity and the subsequent health effects. The appearance of a cancer village is the result of the spatial-temporal distribution of human-land interactions, whose emergence manifests as an issue of human health and geography. The economic and pollution pathways are complex and defy simple solutions, but need to be rigorously investigated to understand and respond to the health effects, especially chronic disease, of urbanisation in Huaihe River Basin of China.

Based on the pollution utility relationship we found that "cancer villages" not only being affected by cities but also affect cities in the indirect relationships. We believe that "cancer villages" have a high incidence of malignant disease not just because of the pollution from its surrounding cities but may also due to the faraway city through the network. Further evidence of the pollution of water environment will adversely human health effects that may lead to the occurrence of gastrointestinal cancer from our research.

Policies to mitigate the adverse health effects of urbanisation need to meet the health-care needs of highly vulnerable populations, and must follow up these populations as they potentially transfer health-care burdens to cancer villages. The next decade of urbanisation in China will demand innovative health policies that address the needs of residents living in big cities while providing health services for people who remain in surrounding small urban areas or villages in river basin.

\section{Acknowledgments}

This work is supported by the Fund for Innovative Research Group of the National Natural Science Foundation of China (Grant No. 51421065), National Natural Science Foundation of China (Grant No. 41471466), the Fundamental Research Funds for the Central Universities. Sergio Ulgiati also acknowledges the contract by the School of Environment, Beijing Normal University, within the framework of the National "One Thousand Foreign Experts Plan".

\section{Appendix A. Supplementary material}

Supplementary data associated with this article can be found, in the online version, at http://dx.doi.org/10.1016/j.apenergy.2016. 06.132 .

\section{References}

[1] The State Council Information Office of the People's Republic of China Government press conference symposia 2004. Beijing: China Intercontinena Press; 2004.

[2] Chen Z. Report on the third nationwide retrospective mortality survey in China. Beijing: Peking Union Medical College Press; 2008. p. 11-12.

[3] Chen Y, Ebenstein A, Greenstone M, Li HB. Evidence on the impact of sustained exposure to air pollution on life expectancy from China's Huaihe River Policy. Proc Natl Acad Sci 2013;110(32):12936-41.

[4] Yin J. Dozens of "Cancer Villages" in Huaihe riven basin. Township Forum 2007:8:22.

[5] Cao SW. The confusion and outlet of "cancer villages": take Wuli Village in Zhejiang Province as an example. Intelligence 2010;19:169.

[6] Gong SS, Zhang T. Temporal-spatial distribution changes of cancer villages in China. China Popul, Resour Environ 2013;23(9):156-64.

[7] Liu GY, Yang ZF, Chen B, Ulgiati S. Emergy-based urban health evaluation and development pattern analysis. Ecol Model 2009;220(18):2291-301.

[8] Liu YB, Li RD, Song XF. Summary and comment of the correlation study of urbanization and urban eco-environment. China Popul, Resour Environ 2005;15(3):55-60.

[9] Al-Kharabsheh A, Ta'any R. Influence of urbanization on water quality deterioration during drought periods at South Jordan. J Arid Environ 2003;53 (4):619-30

10] Zhou SX. China environmental state bulletin in 2008Available from: <http:/ www.mep.gov.cn/gzfw/xzzx/wdxz/200906/P020090609397520028674.pdf> 2008

[11] DeNooyer TA, Peschel JM, Zhang ZX, Stillwell AS. Integrating water resources and power generation: the energy-water nexus in Illinois. Appl Energy 2016;162:363-71.

[12] Nanduri V, Saavedra-Antolinez I. A competitive Markov decision process model for the energy-water-climate change nexus. Appl Energy 2013:111:186-98.

[13] Zhang YP. Urbanization and urban water environment. Urban Environ Urban Ecol 1998;11(2):20-2.

[14] Gao MJ, Tian HF, Xue LF. Study on the relationship between urbanization proceeding and environmental evolution of water resource. J Anhui Agricult Sci 2011;39(6):3501-3.

[15] Wang XY, He PP, Wang LL, Li LF. Impact analysis for the sustainable development of industrial pollution in rural areas. Rural Econ Sci-Technol 2012;23(10):18-20.

[16] Xu SL. Re-thinking of reestablish eco-system health on watershed. Yunnan Geogr Environ Res 2011;23(6):70-3.

[17] Burgess EW. The growth of the cityAvailable from: <http://isites.harvard.edu/ fs/docs/ icb.topic10509 93.files/2-15\%20-\%20Ernest\%20Burgess\%20-\%20The\% 20growth\%20of\%20the\%20City.pdf $>1925$.

[18] Myrdal G. Economic theory and under-developed regionsAvailable from: <http://duncankennedy.net/documents/Is-Pal/Second-Syllabus/G.\%20Myrdal, $\% 20$ Economi c\%20Theory\%20and\%20Underdeveloped\%20Regions.pdf $>1957$. 
[19] Hirschman AO. The strategy of economic development. New Haven, Conn.: Yale University Press; 1958.

[20] Ahlfeldt G. If Alonso was right: modeling accessibility and explaining the residential land gradient. J Reg Sci 2011;51(2):318-38.

[21] Arauzo-Carod JM, Liviano-Solis D, Manjón-Antolín M. Empirical studies in industrial location: an assessment of their methods and results. J Reg Sci 2010;50(3):685-711.

[22] Liu YS, Zhou Y, Wu WX. Assessing the impact of population, income and technology on energy consumption and industrial pollutant emissions in China. Appl Energy 2015;155:904-17.

[23] Xing Q Chen C, Shi H, Shi P, Zhang YZ. Estimation of chlorophyll-A concentrations in the pearl river estuary using in situ hyperspectral data: a case study. Mar Technol Soc J 2008;42(4):22-7.

[24] Forrer J, Kee JE, Newcomer KE. Public private partnerships and the public accountability question. Publ Admin Rev 2010:475-84.

[25] Chen WQ, Zheng RS, Zhang SW, Zhao P, Zeng HM, Zhou XN. Report of cance incidence and mortality in China. People's Medical Publishing House; 2014.

[26] Wang SF, Lin JX, Shi SY, Zhang J. Geological disease caused by ecological environment: an example of Cancer Village in Shannxi province. Environ Protect 2001;5:11-3.

[27] Lin YS. Study on the pollution of underground water and high prevalence of cancer in Kangmei Village of Dongshan, Fujian. Strait J Prevent Med 2006;2 (2):129-33.

[28] Wang LJ, Hu YS, Zhou MG, Ge H. Analyze the death level and changing trends of malignant tumors in four counties (districts) with "cancer high-incidence villages" reported by media. Pract Prevent Med 2009;16(006):1740-3.

[29] Lu CY, Zhong XH. Analysis of temporal and spatial rule of cancer village distribution of in China. Modern Agricult Sci 2009;7:243-4.

[30] Sun YF. Study on the distribution of Dancer Villages in China. WuHan: The Department of Geography of Huazhong Normal University; 2009.

[31] Liu L. Made in China: cancer villages. Environ: Sci Policy Sustain Develop 2010;52(2):8-21.

[32] Yu JL, Zhang SO. Analyzing China cancer villages phenomenon and the problem of environmental pollution and health made by it. In: Annual meeting of environmental science academy of China in 2009. Beijing: Beijing University of Aeronautics and Astronautics Press; 2009. p. 882.

[33] Chen WW, Zheng RS, Baade PD, Zhang SW, Zeng HM, Bray F, et al. Cancer statistics in China, 2015. CA Cancer J Clin 2015;66(2):115-32.

[34] Zeng H, Zheng R, Guo Y, Zhang S, Zou X, Wang N, et al. Cancer survival in China, 2003-2005: a population-based study. Int J Cancer 2015;136:1921-30.

[35] China Statistics Bureau. China's environmental statistics yearbook 2001. Beijing: China Statistics Press; 2002.

[36] Tobler WR. A computer movie simulating urban growth in the Detroit region. Econ Geogr 1970;46:234-40.

[37] Gu CL, Pang HF. Study on spatial relations of Chinese urban system: Gravity model approach. Geogr Res 2008;27(1):1-12.

[38] Tang J, Ma XD, Zhu CG, Qian C. Study on urban economic region of Huaihai Economic region based on economic contacts. Urban Stud 2009;5:18-23.

[39] Jin G, Jin L, Wang ZQ Huang ZH. Research on the spatial structure model of metropolitan circle land price based on the gravity model. J Anhui Agri Sci 2009;25:12123-4.
[40] Lu DD. Location theory and methods for regional analysis. Beijing: Science Press; 1988.

[41] Patten BC, Bosserman RW, Finn JT, Cale WG. Propagation of cause in ecosystems. In: Patten BC, editor. Systems analysis and simulation in ecology. New York: Academic Press; 1976.

[42] Ulanowicz RE. Growth and development: ecosystem phenomenology. New York: Springer-Verlag; 1986.

[43] Ulanowicz RE. Ecology: the ascendent perspective. New York: Columbia University Press; 1997.

[44] Ulanowicz RE. Identifying the structure of cycling in ecosystems. Math Biosci 1983;65:219-37.

[45] Patten BC. Network ecology: indirect determination of the life-environment relationship in ecosystems. In: Higashi M, Burns TP, editors. Theoretical studies of ecosystems. Cambridge: Cambridge University Press; 1991.

[46] Higashi M, Patten BC. Dominance of indirect causality in ecosystems. Am Nat 1989;133:288-302.

[47] Patten BC, Higashi M, Burns TP. Trophic dynamics in ecosystem networks: significance of cycles and storage. Ecol Model 1990;51(1-2):1-28.

[48] Fath BD, Patten BC. Review of the foundations of network environ analysis. Ecosystems 1999;2:167-79.

[49] Fath BD, Patten BC. Network synergism: emergence of positive relations in ecological systems. Ecol Model 1998;107(2-3):127-43.

[50] Scharler UM, Fath BD. Comparing network analysis methodologies for consumer-resource relations at species and ecosystems scales. Ecol Model 2009;220(22):3210-8.

[51] Fath BD. Distributed control in ecological networks. Ecol Model 2004;179:235-45.

[52] Fath BD. Sustainable ecosystem patterns. In: Modelling socio-natural systems symposium, Stockholm, Sweden.

[53] Fath BD. Community-level relations and network mutualism. Ecol Model 2007;208:56-67.

[54] Ulanowicz RE. Quantitative methods for ecological network analysis. Comput Biol Chem 2004;28:321-39.

[55] Wulff F, Field JG, Mann KH, editors. Network analysis in marine ecology: Methods and applications. Coast Estuar Stud 1989;32:284.

[56] Christensen V, Pauly D, editors. Trophic models of aquatic ecosystems. ICLARM conference proceedings, vol. 26. p. 390.

[57] Borrett SR, Fath BD, Patten BC. Functional integration of ecological networks through pathway proliferation. J Theor Biol 2007;245:98-111.

[58] Dunne JA. The network structure of food webs. In: Pascual M, Dunne JA editors. Ecological networks: linking structure to dynamics in food webs. Oxford: Oxford University Press; 2006.

[59] Chen SQ Chen B. Urban energy consumption: different insights from energy flow analysis, input-output analysis and ecological network analysis. Appl Energy 2014;138:99-107.

[60] Gao CX, Sun M, Shen B. Features and evolution of international fossil energy trade relationships: a weighted multilayer network analysis. Appl Energy 2015; 156:542-54.

[61] Lobanova ES, Finkelstein S, Herrmann R, Chen YM, Kessler C, Michaud NA, et al. Transducin gamma-subunit sets expression levels of alpha- and beta-subunits and is crucial for rod viability. J Neurosci 2008;28:3510-20. 